\title{
Toward a theory of ecosystem well-being
}

\author{
Marc Fleurbaey $^{1}\left([) \cdot\right.$ Christy Leppanen ${ }^{2,3}$
}

Accepted: 8 May 2021 / Published online: 21 May 2021

(c) The Author(s) 2021

\begin{abstract}
Can the main methods of social welfare analysis be extended to cover multiple species? Following a non-anthropocentric approach, we examine the pros and cons of various objective and subjective methods of well-being comparisons across species. We argue against normalizing by specific capacities but in favor of taking account of individual preferences and specializations. While many conceptual and practical difficulties remain, it appears possible to develop methods for the assessment of collective well-being of multi-species communities and ecosystems.
\end{abstract}

Keywords Social welfare · Well-being · Interpersonal comparisons · Hedonism · Functionings $\cdot$ Animal preferences

JEL Classification D63 · D71

\section{Introduction}

Social welfare analysis, as practiced by economists and related scholars and practitioners (Adler, 2013), is focused on human beings and derives the value of ecosystems solely from the services such systems provide to the human population. This anthropocentric approach may be able, in principle, to achieve good standards of stewardship for the environment, but its philosophical foundations are deeply questionable. What makes the human species so special that it is the only source of value?

Marc Fleurbaey

marc.fleurbaey@psemail.eu

Christy Leppanen

Christy.Leppanen@fda.hhs.gov

1 Paris School of Economics, Paris, France

2 University of Tennessee, Knoxville, USA

3 The center for Tobacco Products (CTP), FDA, Silver Spring, USA 
Expert assessments of ecosystem services generally recognize non-anthropocentric values. For instance, the Mapping and Assessment of Ecosystems and their Services (MAES) by the European Union mentions that "nature also has an intrinsic value beyond its utility to mankind" (Maes et al., 2014), although this idea has disappeared from its more recent documents. The IPBES, in its 2019 Report, does feature the intrinsic value of nature, alongside its contributions to people and to a good quality of life, but a framework to adjudicate the trade-offs between these various values, especially for better decision-making, remains elusive.

In this paper we set out to explore the possibility of abandoning anthropocentrism completely. The consequences of anthropocentric thinking can be compared to those of other domination frameworks. The dramatic history of colonialism and slavery suggests that when a subpopulation grants itself overall responsibility over a larger population, and considers itself to be the best steward of the whole, it actually directs most resources toward its narrow interests and can be so oblivious of the interests of the "other" as to put them into a state of inferiority and dependence from which it takes generations to recover. Even genocide has proved to be possible in this context. This is exactly what we now observe with the extinction of many species under the pressure of human invasive and careless activities, and the reduction of many animals into a state of complete dependence, even in shelters designed to protect them.

It is not surprising to have a large gap between the biased and prejudiced practices of administrators and the normative theories that would recommend better stewardship while remaining anthropocentric. But anthropocentrism in normative concepts is suspect, unfounded, ominously similar to the old religious and racist doctrines that gave the White Christian Man the right to own the Earth, and apparently too weak as a normative compass to fight pervasive destruction in the age of mass extinction. A familiar defense of anthropocentrism is that human beings are de facto in charge and are the only ones able to debate policy options. This defense confuses values and instruments. When vulnerable human beings (children, dependent elderly, mentally disabled people) depend on more able companions to make decisions for themselves, it would appear repugnant to rely on able-centric normative frameworks. Being in charge does not grant any superior normative value.

Social welfare analysis is therefore in urgent need to shed its century-old anthropocentrism. This paper examines the scope of the reform that this move would require. The key question is whether the concepts of social welfare analysis need a complete overhaul, or can be extended. Indeed, the main task of social welfare analysis is to trade-off the interests of various members of the population under consideration. Comparing how well-off different human beings are is actually not so simple (Fleurbaey \& Hammond, 2004), and has led many economists to despair that it was even possible to do on a rational, non-arbitrary basis. Different human beings differ in their abilities, needs, and goals in life, so that comparing their situations in terms of success or advantage is far from obvious. But various methods have been designed to perform that delicate task.

Comparing individuals from different species is admittedly more difficult because differences in abilities, needs and goals are even larger and more profound. But it remains to be seen within this context whether inter-species comparisons are of a 
different nature than intra-species comparisons. This is the question we study in this paper. To do so, we review the main approaches to interpersonal comparisons that have been imagined in welfare analysis for human beings, and examine if they can be extended to comparisons across species as well.

This project necessarily encompasses the need to build methods for intra-species comparisons of well-being in non-human species. Interestingly, just as for humans, diversity of personalities is standardly recognized for other species. Biologists recognize, consider, and even value intra-species individuality in various species when varying performance by particular individuals defies our expectations and needs. For instance, personalities are recognized as incompatible when a female and male Guam kingfisher placed together in an aviary fail to reproduce. In these instances, one tries to accommodate for preferences of particular individuals towards the goal to create more individuals and prevent species extinction. Mate preference is wellknown in many taxa, even mice (Asaba et al., 2014) and fruit flies (Narraway et al., 2010), and personalities have even been documented in fish (Cerqueira et al., 2016; Rey et al., 2015).

We adopt the working premise that belonging to a particular species does not justify any differential treatment in social welfare analysis, and that only the individual characteristics of the organisms under consideration are relevant for such an exercise. We will not try to justify this premise here-e.g., some strongly debate that some species such as mosquitoes (Pugh, 2016) deserve any such considerationbut it serves as a useful baseline to start a non-anthropocentric approach. But we are willing to limit the scope of our inquiry to individuals with certain characteristics. For instance, rocks do not seem to have anything like abilities, needs and goals. Restricting value to living organisms appears a defensible stance, at least in a first step. It may also happen that certain comparisons are possible only between organisms sharing certain characteristics. For instance, viruses and bacteria may lack certain characteristics for certain comparisons. Plants and invertebrates may be easier to include but still harder than vertebrate animals, and among vertebrates some may be easier to include than others. We are willing to allow for certain comparison methods to be applicable only to a subset of organisms. Some methods may even work only for subsets of human beings. Analysis of the scope of different comparison methods for adaptation to considerations of well-being in non-human organisms is the ultimate goal of this project, and this paper is a first step in that direction.

There is a burgeoning literature in welfare economics which examines how to incorporate the well-being of organisms other than humans into the traditional framework. Eichner and Pethig (2006) argue that instrumental approaches can be quite effective and they question the need to assign intrinsic value to non-human organisms when human beings are sufficiently concerned with their well-being. In contrast, Johansson-Stenman (2018) argues in favor of assigning substantial, possibly equal, weight to the hedonic well-being of humans and other organisms, tracing the origins of this approach to Bentham's utilitarianism and providing evidence of the growing prevalence of such views in the public with a survey (in Sweden).

While our paper builds on human-focused welfare analysis, it also directly connects to an ongoing debate in conservation studies about whether the traditional approach to conservation is instrumentalist, collectivist, and nativist (Wallach et al., 
2018, Driscoll \& Watson, 2019). These three lines of criticism all object to a different kind of failure to respect the interests of each individual member of the species under conservation management. Instrumentalism treats them as means for goals that have nothing to do with their own interests (e.g., one species is used to destroy another); collectivism uses larger goals (e.g., preservation of wildlife collectives) as justification for actions against individuals; nativism prioritizes species according to historical precedence considerations that have no normative value except the mere preservation of the status quo.

With respect to this debate, our own approach explores the possibility to have a species-neutral, as well as status-quo-independent, approach which duly acknowledges the interests of every organism in the collective, without giving species and their historical record as such an independent valuation beyond the thriving of the individual members and the communities. Instrumentalism and a mild form of collectivism are not totally excluded by our approach, though, since in trading-off the conflicting interests of different members or groups of members, it may in some circumstances appear beneficial for the whole collective well-being to sacrifice the well-being of some individuals for the sake of others. But at least, strict collectivism, which is focused on preserving species at any cost on individuals, as well as nativism, which differentiates species according to extraneous (historical) characteristics, are excluded at the outset in our exploration here.

There is an important literature on animal welfare (Mench, 2019), and in this context we default to the term "animal" to align with that literature, but our considerations extend to all non-human organisms. Animal welfare frequently focuses on farm animals and often takes an indirect anthropocentric perspective, in the sense that it seeks to respond to the concerns of the human public about animal welfare. For instance, in Appleby et al. (2018), one reads that "since concern about the welfare of animals stems from the fact that they are sentient (capable of feelings), then feelings have to be a major part, perhaps the central part, of their welfare" (K788-790). ${ }^{1}$ This means that the definition of animal welfare is then guided by human concerns for animals. While we reject such a conceptually instrumental, anthropocentric approach, this literature is nevertheless very useful in providing concrete methods for measuring the well-being of non-human organisms and we will refer to it throughout this paper.

The paper is structured as follows. The next section introduces to the structure of the type of social welfare analysis that is the workhorse of this paper. In particular, it explains why in this paper we focus on the problem of well-being comparisons among individual organisms from different species and largely leave aside the problem of the evaluation of the distribution of well-being as well as questions of population sizes. In Sects. 2-5, we examine four approaches to the measurement of advantage or well-being: command over resources, hedonic well-being, objective list methods, and preference-based methods. These are the prominent methods in current social welfare analysis (Adler, 2019; Adler \& Fleurbaey, 2016). In Sect. 6, we scrutinize the important issue of rescaling the measures of functionings for

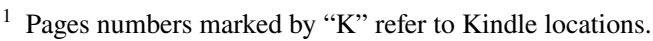


species with different abilities, such as longevity. This problem raises an apparent dilemma which is quite important, and echoes similar difficulties appearing among human beings with unequal capacities or with disabilities.

\section{The structure of evaluation of a collective state}

Usual terminology in social welfare analysis sounds awkward in the extended context of our study. "Social" welfare refers to the human "society" and it is not obvious that the word "society" should be extended to apply to full eco-systems. We will therefore talk about "collective" state and "collective" welfare in order to refer to the evaluation of the state of affairs involving a collection of different individual organisms that may belong to different species and may or may not be in a "social" relation of any sort. The word welfare can be retained here, provided that it is given the most general interpretation, referring to the state of being well, or well-off. It need not be understood in terms of subjective perceptions that are more or less specific to organisms with high levels of cognition.

These preliminaries being clarified, we can introduce two alternative approaches to the determination of collective welfare. The first approach directly exports the most common method of welfare economics to the multi-species collective, treated as a single collection of individuals. This approach involves two steps. The first step assesses and compares the situation of every individual member. It produces something like a measure of well-being for each individual, or at least a comparative order of the individuals ${ }^{2}$ under consideration. The second step makes an assessment of the collective distribution, by aggregating the individual situations into a collective measure. In this second step, the key normative question is the degree of priority that is given to the worse-off in the distribution. We will mostly focus on the first step here, because this is a key hurdle. Once all individuals have been put on the same scale (or order) of well-being, aggregation can proceed without considering any other elements than their well-being or their rank in the order. It can "easily" be species-blind. It is worth recalling, however, that the aggregation method determines the type of comparisons that is needed. With a strong priority for the worse-off, the comparisons of levels are of prime importance. In contrast, when a simple addition of individual well-being indexes is made, there is no need to worry about levels and variations of well-being are brought to the fore.

The second approach that can be considered is closer to how biology and conservation efforts usually view ecosystems. In biology, a 'community' is defined as a group of interacting individuals of different species and a 'population' as a group of individuals of the same species sharing the same distribution. We use the term 'species' loosely to designate the lowest appropriate discrete taxonomic level and acknowledge the possible use of other measures, e.g., gene frequency or phenotype, to inform diversity. 'Ecosystem' then refers collectively to the biological community and its interactions with its environment. In this paper we are interested in a measure

\footnotetext{
${ }^{2}$ The term "individual" will be used here as a short-hand for "individual member" of the collective.
} 
of collective welfare that applies to collections of organisms at any scale, potentially including several communities that are not interacting. Now, according to this second approach, there are three steps in the construction of the measure of collective welfare that might be contextualized by comparison with management considerations of an endangered species. Consider the following with reference to elephants: The first step is identical to the first approach and yields a list of individual wellbeing indices for all members of the collective (and its component communities and populations). But then the aggregation proceeds in several steps. First, aggregation is made within every population of each species, then across all populations of each species (if there is more than one population for some species in the relevant ecosystem), and then aggregation of species well-being is performed across all species. One could add an intermediate level that would aggregate the welfare of all populations in each local community before going to the higher level. The species-level aggregation does not require that the individual well-being indices be comparable across species, but the final aggregation requires that the comparison can be made across species' collective welfare, and we believe this cannot be made without having a way to compare the well-being of individuals across species. There are three elephant species: Asian, African bush, and African forest. Imagine that one computes a measure of collective welfare for humans, and a specific one for each of the three elephant species. How could the two measures be aggregated without having a way to compare the well-being of a single Asian elephant to that of a single African bush elephant, as well as the well-being of a single human to that of a single Asian elephant? Obviously, if each species had only one individual member, there would be no way to avoid inter-individual comparisons across species. This seems to be the case even when species have many members.

What is interesting about this second method, though, is that the exercise of building a comparison method within a given non-human species (say, Asian elephants) might take a slightly different turn if the perspective of aggregating over species at some later stage was absent. We will focus on interspecies comparisons in this paper, but a slightly different project could explore the possibility to develop particular methods of comparisons that are suited especially for certain species. Assuming that such methods would become available, it is not obvious how they could be harmonized for an ulterior aggregation across species. We leave this question for further research.

Comparisons between persons or organisms are sometimes thought of as referring to a pre-existing magnitude, "well-being," which is out there objectively, and that analysts should only strive to uncover. But this misinterprets the purpose of collective welfare analysis. Such analysis is meant to help in producing better states of the collective, and improving collective states does not necessarily depend only on the distribution of an empirical notion of well-being. That may depend on fairness principles, such as giving equal opportunities to individuals. For instance, John Rawls' conception of social justice revolves around giving individuals resources that they can use for their life purposes, and the compass for a better state is about the distribution of resources, not about the distribution of achieved well-being in any ordinary sense. Rawls (1982) vehemently criticizes the idea that one could compare the overall success of different people having very different goals in life, arguing 
that this would undermine respect for the fact that their goals are incommensurable. In contrast, giving people equal resources, no matter what their personal goals are, is the model he sets for a just society-it is slightly more complicated actually, as he allows for inequalities that advantage the worst-off, due to incentive effects, but the key point is his rejection of ordinary well-being as the currency of fairness.

Now, one could try to argue that fairness is unlikely to be relevant to tradingoff the conflicting interests of different species bound by interactions very different from our social contracts, unlike human beings in a country (and Rawls didn't even think that fairness was relevant in the same way for human beings across countries, though that is certainly controversial and criticized by cosmopolitan thinkers). One should, however, recognize that some species are so entangled with and dependent on human beings that they effectively are in an interspecies social contract (Donaldson \& Kymlicka, 2011). This is clearly the case for domesticated animals, e.g., pet adult dogs prefer human strangers over unrelated female conspecifics from their household (Mariti et al., 2017), but it also holds to some extent for wild animals in direct interdependence with humans. But not all species are interdependent in this way.

At any rate, there are other philosophical approaches that are also non-welfarist without relying on a Rawlsian-type fairness argument. For instance, Sen's capability approach (Sen, 1992) can be cast in terms of functionings and capabilities (functionings are states or activities of the individual, such as nutrition, safety, travel, and capabilities are sets of functioning combinations that individuals have access to, such as making a trip to a restaurant or instead eating at home), and given a rationale that is mostly about identifying the dimensions of life that we should have reasons to value, and about taking account of the additional value of freedom which justifies the move from achieved functionings to capabilities. Again, this may be seen as differing from involving a positive, empirical approach to well-being, because the valuation of functionings and capabilities is a normative exercise through and through.

Opposite the view that well-being is an empirical magnitude that can be studied as a given object, a tradition in economics has claimed that there is no empirical basis for interpersonal comparisons because of the inscrutability of mental processes (this obviously supposes that well-being is primarily a mental state, which is itself contentious). This tradition has now receded, but one can retain from it the idea that empirical data do not fully determine comparisons, thus opening the door to normative principles (List, 2003; Robbins, 1981).

In conclusion, we believe that one should be open to the analysis of inter-organism comparisons going beyond a positive investigation of well-being, and we actually believe that it is a deeply normative exercise, which decides what counts in analyzing advantage and disadvantage for the purpose of deciding priorities in redistribution of resources and other forms of support among individual members of the collective.

So far, we have adopted the individualistic method of welfare economics and, by extension, treated each living organism as the site of well-being, and therefore the ultimate locus of value. Biologists may question this assumption as being far from obvious. Why do we stop at the level of the organism when DNA/RNA (or amino acids) is truly our common currency and it is from this that we pull our diversity? 
Obviously, we do this because we infer the emergence of cognizance at the level of the organism that is a unique expression of our DNA/RNA, but isn't that, again, anthropocentric or at least organism-centric? Why not protect the gene? Does it make sense to treat isolated cells (bacteria) as organisms and ignore cells that compose multicellular organisms?

These are challenging questions, but the multi-species aggregation question of this paper suggests a way to think through this issue. When one ventures beyond the familiar questions about human well-being and considers a multiplicity of very diverse organisms, the possibility of having multiple layers of value, such that every consequential upper structure adds its own contribution to the value of the whole, appears the most reasonable stance. It would be really odd to declare that no human cell or organ has value by itself while organisms of similar complexity in other species would have some value. And a similar argument applies in the upward direction. A full-blown individual organism, with its own degree of apparent autonomy and sense of purpose, definitely adds extra value to the sum of its components. But then, looking up, why not recognize that a collective of such individuals, which develops its additional layer of complexity, its rich structures, its uniquely collective achievements and purposes, can have a value above and beyond the collection of individual well-being situations? Add to this the observation that what is ordinarily called a human body is the host to at least as many micro-organisms as human cells, and the idea that there is a strict distinction between the "individual" and the "collective" falls apart. For plants and fungi, the notion of individual organism is also often less salient than the network aspects of their life, so that the definition of individuality and even the identification of the level at which selection occurs is not obvious (Clarke, 2011).

If one accepts the idea that a collective of organisms or suborganisms can have additional value through its structure and purpose, it appears understandable why the prevailing assumption is that the source of value resides at the level of the individual organism. There is indeed a big qualitative leap in structure and purpose when one reaches this "individual" level, climbing from the lower level of organs and cells, whereas, going further up above this level, the added structure and purpose is not so striking, and is often downplayed in the dominant culture of the West. In other words, if one had to pick a single level as the site of value, it would likely be the level of the individual. This is of course debatable, and in particular ecologists might disagree, who often refer to the collective of many individuals of many species as the level of value because it provides services, e.g., food, water purification, and climate regulation, and/or because we are incapable of identifying and quantifying value elsewhere. The fuller picture should recognize that other higher or lower levels are independent sites of value, too.

In this paper, we will actually stick to multicellular organisms as the primary site of value rather than a lower level. This is not meant to downplay the value residing at the lower levels, but one can simply assume that the aggregation at the lower levels (cells, amino acids, even particles) is already performed by the organism itself and that whatever value the components of the organism have will be properly accounted through our measure of the well-being of the organism. Of course, this is again, potentially, a controversial stance. For instance, if the gene was the ultimate source 
of value, then the number of organisms sharing that gene would not matter much, apart from the reproductive prospects they would entail for the gene itself. In our approach, we assume that the value of the gene is sufficiently recognized through its contribution to the well-being of the organism it generates. This does not necessarily mean that the gene has a purely instrumental value, but that the value of particular amino acids, nuclei and cells is suitably aggregated through a measure of well-being of the organism, through the outcome of the interactions and particular structural patterns that make up the organism.

One may then ask why we focus on the individual organism and do not go to an upper level directly (e.g., the species). If there was a convenient, direct way to assess the well-being of a population of individuals, one might as well argue that the value of each organism is sufficiently recognized through its contribution to the collective assessment at the population level. But there is no such easy and direct way, and our project here is precisely to construct a way to make such a collective assessment, and because of the lack of a direct route, we follow an approach based on elementary steps involving the lower level of the individual.

Welfare economics has generally failed to recognize a truth that hides in plain sight among its concepts. "Social welfare" is not just a summary of the collection of individuals' well-being, it adds supplementary value, at the very least through the quality of the distribution of well-being in the population. The idea that both the individual organism and the collective are sites of normative value transcends the opposition between a "collectivist" approach and an "individualistic" approach. This normative shift from the purely individualistic approach to a multi-level approach does not have much impact on the rest of our analysis, but we think it is important to mention, because this shift is forced upon us by the multi-species setting which includes widely different levels of complexity.

Although this is more speculative, we suspect that this multilevel normative approach may also make it possible to better observe, recognize and value the synergies between the thriving of the individual and the thriving of the collective. For human beings, social integration benefits individuals in many vital ways. Examples of beneficial social integration in some non-human taxa are also broadly known. For instance, the concept of "safety in numbers" is demonstrated by predator evasion by schooling fish and herds of ungulates, and by primates that vocally warn each other of imminent threats.

Less well-known benefits of group aggregation are evident in apparently "lower" organisms. For example, a sea anemone contracts, shielding its tentacles from harm, when a conspecific close by is wounded (Howe \& Sheikh, 1975) and normally unicellular green algae Scenedesmus form clusters to hinder predation by zooplankton (Lampert et al., 1994). Aphids communicate attack by predators or parasitoids via cornicle secretions that alert their conspecifics, e.g., to disperse or attack (Pickett et al., 1992). Like animals, plants "pay attention" (Marder, 2013) and adapt (Novoplansky, 2019) to their environments, perceiving and responding using sensory neural networks (Baluska \& Mancuso, 2009), and benefit from membership in societies, e.g., communicating herbivore damage triggering responses that protect neighboring conspecifics (Benevenuto et al., 2018) and even heterospecifics (reviewed by Heil \& Karban, 2009). In general, in each case the individual benefits from membership in 
the larger group. In some cases, it is also evident that the sum of the parts, i.e., the outcome of interactions between individuals, is greater than the contribution of each individual. For instance, like humans, ants are renowned for orchestrated collaboration between varying groups of individuals leading to impressive feats such as architecture (Tschinkel, 2015) and farming (Mehdiabadi \& Schultz, 2009). Outcomes of interactions between individuals are not additive, but synergistic. Something new is derived from the collective.

It therefore appears important to go beyond the observation and measurement of individual functionings and to also register the state of the community, above and beyond the aggregation of individual measures of well-being. As an example, consider the stability of an ecosystem and its vulnerability to human activity. Anthropogenic impacts to collectivities of non-human individuals sometimes become evident in altered trophic cascades. Prominent features in ecological communities, trophic cascades reflect nutrient flow in food webs. For example, a plant is eaten by a snail that is eaten by a crab. Predation pressure by the crab limits snail populations and therefore limits damage to the plant. However, when the crab population crashes, e.g., owing to overfishing or spread of a pathogen that impairs or eliminates crabs, plant populations also crash because snail populations explode. Its diet expended, the snail population might then subsequently crash. While there is some controversy over depiction of the unimpacted system as "stable," increasing instances of such "instability" in ecological communities owing to human disturbance is a reasonable characterization, as is portrayal of such scenarios as "unhealthy," therefore deviating from well-being. Observe how this example shows that the collective that adds value to the individual values can involve several species, not just several individuals from the same species.

These observations reveal parallels between human societies and their analog, non-human communities (the living components of ecosystems), in two ways, since the individual is benefitted by the community, and reciprocally the community benefits from the contribution of the individual. Social information in ecological systems is indeed linked to increased population size and species persistence, coexistence, and diversity, i.e., information shared by individuals benefits the population, species, and so on (Gil et al., 2019). A relevant measure of a possible common "wellbeing" currency in human and non-human species must fully incorporate the outcomes of socially derived synergistic interactions.

In this paper, we focus on what is called "interpersonal comparisons" in social welfare analysis, and leave aside two other key ingredients of social welfare analysis: the evaluation of the distribution (i.e., questions about priority for the worse off) and of the population size (i.e., population ethics). We consider that inter-species comparisons is the main roadblock at the moment, whereas the available methods for aggregating individual measures of well-being at the population level are likely to be easily adjusted once comparisons are made possible in a satisfactory way. It is true that the type of comparisons that is needed (e.g., comparing well-being levels or gains and losses) depends on the type of aggregation that is performed at the population level, and we will assume in this paper that the ideal method would make it possible to measure well-being in a way that allows any type of comparison. In practice, we will often focus on comparisons of levels in examples and more concrete 
illustrations, implicitly assuming that social aggregation will display a concern for the worse-off. But the comparison methods that are reviewed in this paper are amenable to comparisons of gains and losses as well.

The other important aspect of the aggregation exercise that we will not examine in this paper is the assessment of the size of populations, communities and larger collections of organisms. This is of course an essential issue for the analysis of the health and sustainability of ecosystems. Our objective in this paper is indeed to contribute to the assessment of biodiversity. But we focus here on one particularly difficult aspect of biodiversity, which is about how to compare and adjudicate the potentially conflicting interests of different organisms. The preservation of populations and communities over long periods of time involves additional considerations of sustainability of ecosystems which have more to do with the physical constraints that govern the dynamics of ecosystems than with the normative question of assessing and comparing the well-being of the individual organisms. There are also important normative questions of "population ethics" (an important field in moral philosophy and welfare economics, see Arrhenius forth.), which have to do with whether large populations are good in themselves because they represent greater total quantities of well-being, or instead one should focus on the average well-being and be indifferent to the number of individuals per se. We ignore these issues here, but they are related to an important distinction between K-selected species and r-selected species. The former have a limited number of offspring and parents invest in nurturing and protecting them until a certain age, whereas the latter spread a high number of descendants (typically in the form of eggs) and do not generally play any role in the development of their offspring. Obviously, the human species (and all mammals) belong to the first category. But one wonders if the importance of the individual organism that is a key element of the ethics of collective well-being is not a reflection of a specific feature of the K-selected category. Population ethics is about the number of such individuals. But the r-selected category is designed to endure a staggering mortality rate (before reproductive age), and the meaning of the size of the population should perhaps be understood differently for this category. Moreover, as noted earlier, the very idea of counting the number of individuals is problematic for species in which the notion of individual is fuzzy (especially plants and fungi). We leave these questions for future investigation.

\section{Resources}

The analysis of social welfare (for human beings) is often, in practice, confined to looking at the distribution of income or wealth. While this is admittedly narrow, it can be defended as a good proxy of the command over resources of different individuals and social groups, as well as a good proxy for social status more broadly construed. It may seem incongruous to examine this approach in the context of extending the evaluation to other species who do not participate in market transactions and do not depend on earning income through such transactions to sustain their consumption. However, a brief consideration of this approach suggests interesting observations. 
First, command over resources is not a crazy concept for living organisms. Abundance and scarcity are as relevant to non-human organisms as to human beings, and success in life largely depends on that - at least on average, i.e., ignoring accidents, health problems unrelated to that, and resource curses (i.e., a nefarious effect of abundance when it destabilizes the system in which the contemplated population usually thrives).

Second, measuring command over resources is complicated when market valuation is not available. And even when it is available, it may not be adequate. For instance, damages to crops done by wild animals can be valued through the corresponding economic value of crop loss, but this measure represents the externality on human beings, not the value to the offending animals themselves. Ideally, the valuation of resources should be done by looking at the marginal impact of such resources on the collective objective that guides the evaluation. In standard economic analysis, it is common to use the "shadow prices" of resources to assess their true value, and this refers to the impact of these resources on the social objective. This is fine, but raises a circularity problem. If we need prices to value the resources controlled or used by different individuals, so as to measure their well-being and ultimately plug this measure of individual well-being into the measure of collective welfare, this means that the measure of resources cannot serve as an input to the construction of the measure of collective welfare, because it instead appears as an output. One then needs another measure of individual well-being, written as a function of the multidimensional resources under consideration, in order to be able to compute "prices."

Third, it makes sense to examine inequalities of resources among individuals with similar needs, but much less so when needs are heterogeneous. This is already a very common and consensual observation in standard economic analysis of income inequalities. Corrections for household size, for instance, are made to take account of the economies of scale obtained in larger households. Disabilities and health expenditure inequalities raise similar issues. Across species, this problem is much more severe. Some species with smaller bodies and smaller energy needs can thrive with much less resources than other species-even if, relative to their weight, their energy needs are often greater than larger species. Climate conditions can also interfere with energy needs. This again creates a circularity problem. In order to calibrate the need coefficients to make different species comparable, one needs a scale of thriving that determines how different quantities of resources can be considered equivalent across species.

Can the equivalence scales used for household size and disabilities serve as a source of inspiration to calibrate the resource needs of different species? This seems unlikely. Equivalence scales have often relied on methods that look at the share of food in expenditures or at subjective perceptions of financial ease, and such methods cannot be extended to other species. However, another approach to equivalence scales relies on individual preferences about consumption of private and public goods within the household, and this type of method is discussed in greater depth in Sect. 5. In the case of cross-household comparisons, it involves seeking the level of resources that an individual would need as a single to reach the same living standards as in the current situation. For instance, in a couple one shares rooms, heating, equipment and so on, and living alone would require more than half the couple's 
income to keep the same standard of living. This makes good sense for comparing life across different household environments for a given person, but the problem of comparing across different physiological needs appears different. More on this in Sect. 5.

In conclusion, although command over resources is not as farfetched an approach as it might seem at first glance, for application to other species, it nevertheless meets serious difficulties and ultimately must rely on a deeper notion of well-being, such as those examined in the next sections. There are related alternatives, some of which will be examined in Sect. 4 dealing with the objective list approach. But one that does not seem to have received much attention is the idea to look at energy consumption. Optimal foraging theory offers an example of how this could be fleshed out, within a given species. Anthropogenic deviations from optimal foraging theory might also indeed perhaps be characterized as deviations from well-being. According to optimal foraging theory, a maximum net rate of energy gain is obtained by the ideal forager by optimally allocating energy and time to necessary foraging components, such as prey searching, pursuit, and capture. Any detraction from optimal foraging would therefore translate to energy loss reflected in a diminishment in health and therefore well-being (e.g., fatigue, disease, or reduced fecundity). An environment that differs from natural conditions, e.g., restricted territories or ranges imposed by cages, fences, or limited or altered habitat or prey, might impede optimal foraging (i.e., exclude preferred habitat and associated resources) and might therefore also impede well-being.

Whether this idea could help with inter-species comparisons is much less clear. It is known that energy consumption and command over resources are strongly correlated for humans, and one could treat the former as a good proxy for the latter, including across species, after appropriate scaling taking account of heterogeneous energy needs across species. However, we doubt that this would go very far since it is a very bad proxy for well-being among human beings. The correlation between income and energy consumption is positive, but economic value is not well proxied by the energy content of goods and services. Given that the transition to a sustainable economy invites decoupling economic value from energy consumption as much as possible, it would be awkward to propose energy as the overarching measure of well-being for an ethical assessment of well-being in ecosystems.

\section{Hedonic level}

The hedonic approach equates well-being with good feelings and emotions. It has several advantages for extensions to other species. First, the measurement of feelings can rely on other sources of data than verbal expressions of contentment, such as skin conductivity, hormone concentrations, and similar physiological measures. Ultimately, this approach can be very "objective" (Kahneman, 1999), even if it focuses on the most fleetingly subjective aspect of well-being. Therefore, it can in principle be used to gain some understanding of species that have few discernable means of communicating their feelings by their behavior or are deprived of a sufficiently rich (vocalized or body) language for doing so. Second, 
while there are dimensions of human lives that have little equivalent in the lives of other organisms (although as time goes on the list of functionings that are deemed specific to humans keeps shrinking steadily), there is no doubt that feelings are shared by many species. Third, hedonism is a well-established tradition in well-being scholarship and its applicability to all sentient beings was considered a quality of this approach as early as the time of Jeremy Bentham (1789), the founder of utilitarianism. In modern times, Peter Singer has been a leading advocate of animal rights (see, in particular, Singer, 1975, 2011), arguing that animals, like humans, have interests and that there is no reason to discount their interests just because they belong to different species. Although Singer, in these writings, did not embrace hedonism (he favored a preference-based approach), it is noteworthy that his main argument for considering that animals have interests is that they are sentient beings, along the lines of Bentham, i.e., they can suffer and experience pleasure. (It would be more in line with a preference-based approach to associate animal interests with some form of purposiveness, as we will do later in this paper.)

Hedonism is, actually, strongly criticized because it is arguably a narrow approach to well-being. Hedonists sometimes claim, following Bentham, that happiness is the ultimate goal because all other goals only have an instrumental value through their contribution to happiness, but there is little to back this argument. Admittedly, the satisfaction of any goal may generally contribute to happiness, but this does not imply that the underlying ultimate goal is happiness itself. Similarly, success in life very often contributes to good health, but this does not automatically make health an ultimate goal as such. In fact, one can conjecture that many people place health very high in their priority ranking for life for instrumental reasons, i.e., because a healthy body and a healthy mind is a great help for almost any life plan. Evolutionary fitness is also something that is correlated with many pursuits that organisms, including humans, exhibit, but that does not make fitness or gene reproduction the ultimate goal of individuals.

As far as human beings are concerned, it seems especially dubious to assert that they all have the same goal, and disrespectful to claim that people are mistaken when they believe that their goals are not limited to happiness (theirs and the happiness of people they care about). In fact, people very often undertake hard projects that offer very limited prospects of reward in terms of happiness, but do make sense with respect to broader considerations about the meaning of life. In a non-anthropocentric perspective, it appears reasonable to think that one should allow for a diversity of goals among non-human organisms as well, not only across species, but also within species.

Another worry about hedonism is that it may prioritize the more sensitive individuals over others, both within and across species. If some individuals are "utility monsters" (Nozick, 1974), i.e., if they can transform resources into happiness with much greater productivity than others, their interests will loom large in the allocation of resources. On the other side of the spectrum, hedonism gives little importance to the species or organisms that are not sentient or barely sentient, and this may create an unjustifiable bias against them. In the hedonic approach, plants and fish, which are considered less sensitive (until future research may prove this wrong), do not 
appear high in the ranking of interests, and one may wonder if their interests can be so blithely ignored.

This interest in sensitiveness, in the hedonic approach, might be partly anthropocentric. Human experience revolves around mental states a lot, whereas other species have a different balance between mental and non-mental achievements. Putting exclusive value on the dimension of life that happens to be exacerbated in the human species should perhaps be viewed as biased since it does not have much foundation apart from the (human) intuition that this is a very important aspect of (our human) life. The goal of producing a lot of happiness for super sensitive organisms might miss the point that maximum sensitiveness is not an obviously desirable character trait. Less sensitive individuals may be better equipped to achieve great things in other dimensions. It makes sense to worry about the vulnerability of super sensitive individuals to suffering, but this could entail an argument both against letting them suffer and against promoting sensitiveness.

The importance of sentience and sensitiveness is crucial in the Benthamite tradition about animals reinvigorated by Singer. As Singer argues, this leaves plants aside, as devoid of ethical value if they do not suffer for lack of a central nervous system. But our earlier questioning of the individual organism as the unique locus of ethical value and our questioning of a bias toward sensitiveness suggest that some caution would be appropriate here. There may be something more fundamental to most living creatures than sentience. Let us tentatively call it purposiveness, by which we mean the tendency to adjust one's behavior or development in a particular direction that can be identified as positive for the organism. Plants display this tendency in a less active way than animals, by all appearances, but they do have it, too. Any organism that is driven by such a sense of purpose, such directionality, can be harmed when its purpose is frustrated, and this is independent of sensitiveness or even sentience. The possibility of being harmed is more fundamental, ethically, than the possibility to suffer. Most sentient beings suffer when they are harmed, but this does not imply that suffering is the only morally relevant fact.

Be that as it may, the main obstacle to hedonism may be practical. If one tries to imagine a practical application of the hedonic approach that goes beyond a general defense of the interests of animals against exploitation and maltreatment and actually pins down a way to make precise inter-organism comparisons, things actually appear singularly complicated. The nervous systems of different species differ, which makes it difficult to equate the feelings of a species with those of another. Any physiological measure of hormone concentration, for instance, has to deal with the fact that concentration rates may have different baselines across species (and sometimes even within species). The physiological markers of emotions may even differ substantially across species. Therefore, the possibility to rely on physiological measures does little to help in inter-species comparisons. For organisms that have sufficiently rich behavioral ways of conveying their feelings, one may be able to calibrate the physiological markers to certain benchmark behavioral patterns (depression, restlessness, aggressiveness, vocalizations, playfulness), but this moves the difficulty only one step further. How does one compare the anger of a human being to the anger of another mammal when their ways of expressing it differ substantially (e.g., one shouts, the other bites)? Indeed, Horowitz et al. (2018) argue that conclusions 
from the study of jealousy in dogs are severely limited by the application of questionable interspecies comparisons.

Looking for a precise measure that is inter-species comparable may be too demanding. But consider a less ambitious approach. Suppose one wants to minimize the occurrence of depressive symptoms across species. How does one weigh the relative importance of depression in a human being with depression in a bird? The promise of hedonism was that, since feelings and emotions are universal among sentient beings, they provided the yardstick by which the interests of various types of individuals could be compared. But this is actually not the case. We can identify when an individual from any species shows signs of depression, but this does not help at all in deciding if depression in a hen is as important, or only a fraction as important, as depression in a cow. Additional considerations must be brought to bear, but it is far from obvious where they can come from.

Budolfson and Spears (2020) propose one such method, involving the number of neurons of a typical member of a species, and weighting the well-being of an individual by a function that increases with this number. Well-being itself can be measured in a rough way that equates the usual account of a species thriving with a certain high level and likewise for low levels. Their approach is quite general in scope and is compatible with hedonic and non-hedonic perspectives, but it is quite relevant as a possible breakthrough for hedonism. Indeed, the number of neurons is a parameter that can reflect a hedonic approach to the importance of species, assuming that sensitivity is correlated to the number of neurons. One interesting aspect of their approach is that it takes the weighted sum of individual well-being as the criterion for collective evaluation. Such an additive criterion does not need a comparison of levels of well-being, it only requires a comparison of differences (rigorously, ratios of differences), so that the neuronal weighting can be interpreted as measuring sensitivity in well-being. That is, moving from depressed to thriving is considered more impactful for a species with larger brains.

Budolfson and Spears give examples of increasing functions that could relate the number of neurons to the weights in the aggregate indicator, and do not propose a specific one, so that the weights could increase sharply or only mildly with the number of neurons. This acknowledges the difficulty of linking the number of neurons to any notion of sensitivity. Moreover, as they note, the number of neurons is a crude indicator of the abilities of the brain, since the wiring of the neural network, the interactions, is another important determinant. Species with small brains have displayed astonishing social abilities, for instance.

We conjecture that there is a fundamental difficulty in comparing feelings across species with different brains and different bodies, as well as different evolutionary histories. Within a given species, the substantial homogeneity of body and neural functions makes it reasonable to associate equal behavioral cues with comparable feelings. Even if one can never ascertain what happens in different individuals' minds of the same species, it makes sense, perhaps as a normative principle of equal respect, to equate similar behaviors and physiological patterns with similar levels of well-being and similar priority in our concern for them. Across species, in contrast, the lack of comparability seems to make the barrier insurmountable. One can recognize the presence of various typical feelings across species. Spunt et al. 
(2017) "found no evidence for a uniquely human neural substrate for the attribution of emotion" in functional magnetic resonance (fMRI) studies of humans, other primates, and dogs, and likewise brain mapping shows circuitry at work in emotional signaling, likely following phylogeny, appears highly conserved in groups such as primates (Gruber \& Grandjean, 2017). But one cannot interpret meaning or compare the intensity of feelings in any meaningful sense across species. Suppose one assembles a data set of behavioral and physiological patterns for different species. One could identify for each species a common pattern and take it as the set point for this species under a particular set of circumstances. Then deviations from this pattern would have to be ranked from better to worse, and it is not obvious how to do that but relying on various markers of preferences and fitness might help. Finally, one could look at the distribution of patterns in every species and equate deviations from the set point in terms of fractions of the standard deviation of each species. Once this is done, do we have a good reason to consider that two individuals, say, one standard deviation above their species set point, are equally well off, or that their difference of well-being with individuals currently at the set point is the same? Would multiple comparisons of many set points for more species and/or considering various sets of circumstances further enlighten such a comparison? Regardless, this would essentially assume that the different species are equally sensitive in the relevant sense and that their distributions of hedonic well-being are the same. Unlike comparisons within a given species, no principle of equal respect seems to support making such assumptions across species.

This difficulty, somewhat ironically, echoes a famous century-old debate in welfare economics, alluded to in the first section. Lionel Robbins (1932) expressed deep skepticism about the possibility to compare the intensity of preferences across human beings, on the grounds that every mind is inscrutable to anyone else. This radical stance, motivated by the prevalent behaviorism of the time, has been, by and large, abandoned since subsequent studies of hedonic well-being have shown various ways in which one can measure and compare the subjective state of different human beings. But we conjecture that Robbins' view appears much more challenging across species with substantially different functions and abilities.

Interestingly, Robbins (1981) clarified his views and emphasized that he was not so much against the logical possibility of making comparisons than in favor of a clear recognition that such comparisons, in the context of policy evaluation, must rely on ethical principles guiding priority-setting, and cannot solely involve empirical comparisons of well-being. We have stated a similar view in the first section, and the practical difficulty of making comparisons of hedonic well-being across species may reinforce the importance of this principle. An impossibility to make empirical comparisons need not imply an impossibility to make ethical comparisons in terms of priority. For instance, the method proposed by Budolfson and Spears could be adopted for ethical reasons, treating the number of neurons not as a proxy for an empirical magnitude such as sensitiveness, but as a proxy for the moral worth of the well-being of an organism. It is worth noting that ethical principles can play a role not only in determining priorities out of fairness or similar concepts, but can also help deal with empirical uncertainty. Uncertainty in empirical comparisons, that is inherent in any study of a biological sample representing a larger entity (in this case 
evaluation of some pattern or behavior as an indication of greater well-being), is often tempered by conservative interpretation (here via such guiding ethical principles) when scientists can conclude that data suggest a particular outcome rather than needing to indicate it. For instance, uncertainty about shared sensitivities in humans and non-human primates or dogs suggests similarities that sometimes afford the latter benefits ascribed to certainty associated with the former, the humans.

The literature on animal welfare displays interesting variations on this theme. For instance, in chapter 2 of Appleby et al. (2018), one reads: "Much of the apparent disagreement between people about animal welfare stems from mixing up scientific questions about the actual state of the welfare of animals and ethical questions about how we ought to treat and care for animals. This chapter does not deal with these ethical questions but focuses on the science of animal welfare and on the different approaches taken in the past to understand what animal welfare is and how to assess it" (K780-783). But later in the same chapter, one reads: "The fact that research into animal welfare in large part involves responding to public concerns means that we cannot define animal welfare in a purely scientific fashion without referring to the ethical concerns that the public has about how we treat animals" (K899-901). In other words, while a purely empirical and scientific approach to animal welfare is embraced, it appears impossible to proceed without guidance from the ethical concerns of relevant stakeholders.

\section{Objective list}

The objective list approach, in standard welfare economics, uses uniform weighting systems (of the various dimensions of life attributes) for human beings, and a prominent, though rather crude, example of this approach is provided by the Human Development Index (HDI) developed by UNDP under the inspiration of Sen's capability approach. It aggregates three subindices covering income (GDP per capita), health (life expectancy), and education (aggregating enrollment and school years).

This objective approach has the advantage of being quite simple if one can measure the various components of the index easily, but its weighting system is its Achilles' heel, because the criticism of arbitrariness is hard to avoid, given that there is no conceptual framework for selecting weights in a specific way. A related criticism is that the weights cannot reflect the diversity of values and preferences of the population. For instance, not everyone among human beings values the trade-off between health and consumption in the same way, but the objective list approach would apply the same relative weights to the two dimensions without regard for heterogeneous views in the population. For instance, the HDI imposes a trade-off between life expectancy and GDP per capita that is uniform across the countries listed.

While these issues with weighting appear problematic for human populations, they seem compounded when going over several species. Even before weighting, the mere selection of a list of dimensions seems a daunting task. Should the list be the same for all species? Imagine trying to extend the HDI to other species. GDP per capita is not easy to extend to other species, as we have seen in the previous section. Life expectancy is a concept that easily applies to other species, but how should it 
be calibrated for inter-species comparisons? Should dogs be considered disadvantaged because their lifespan is only about a seventh of humans'? Or should the species "normal" lifespan be taken as the benchmark for each species? For some living organisms, the notion of lifespan is actually not so easy to pin down. For instance, trees can live across centuries, but sometimes involving a network of spinoffs. We will dive into this issue a little more later. Finally, the third dimension of the HDI, education, appears very hard to extend to other species, even if learning, including cultural transmission, does happen in many species.

Standard definitions of animal welfare tend to rely on the objective list approach. As quoted in Appleby et al. (2018), the World Organization for Animal Health describes an animal as having good welfare if it is: "healthy, comfortable, well nourished, safe, able to express innate behaviour, and ... is not suffering from unpleasant states such as pain, fear, and distress" (K811-813). Note that the presence of subjective items in this objective list is not surprising, since elements of mental health naturally appear in such objective lists. One contentious item in this list is the reference to "innate" behavior, since animals can adapt to various changes in the environment and develop behaviors which are not standard but nevertheless beneficial. Domesticated animals and pets, in particular, may have adaptive behaviors which deviate from the typical behavior of their wild counterparts. The innate behavior of predators may be frustrated in an environment in which preys are replaced with abundant prepared food, and food palatability and preferences have been studied for some time, particularly in the context of livestock (e.g., Healy 1964) and invasive species, e.g., Asian shore crabs preferred animal food items over algae (Broussear and Baglivo 2005). But deviations from such innate behavior may not be detrimental to their well-being. An almost equivalent list comes from FAWC (1979), where animal welfare is encapsulated in Five Freedoms: (i) from hunger and thirst; (ii) from discomfort; (iii) from pain, injury or disease; (iv) to express normal behavior; and (v) from fear and distress.

Instead of going from a human index like the HDI toward an animal extension, what about the reverse path? If one considers the lists in the previous paragraph, can they be applied to human beings? Obviously they can, and if most human beings enjoyed the conditions defined in this list we would be in a much better world. However, the lists appear to miss important items for human beings, such as political freedom, freedom of speech and religion, access to education, absence of discrimination. Perhaps the notion of "innate behavior" or "normal behavior" can capture some of these aspects and vary across species to capture important variations of functional abilities and needs. This seems warranted because we recognize such similarity in cognitive neuroscience when animals are used as model systems to elucidate understanding of human emotion and behavior and its biological underpinnings (e.g., Berridge, 2003; Bunford et al., 2017; Lang \& Davis, 2006; Wager et al., 2008).

It is interesting here to bring Martha Nussbaum's list of basic capabilities as a prominent benchmark to which animal welfare lists can be compared. Indeed, her list is meant to contain the basic elements of life that every human being should be guaranteed in a good political regime. Her list includes the following items (Nussbaum, 2018, pp. 9-10): 
1. Life. Being able to live to the end of a human life of normal length; not dying prematurely, or before one's life is so reduced as to be not worth living.

2. Bodily Health. Being able to have good health, including reproductive health; to be adequately nourished; to have adequate shelter.

3. Bodily Integrity. Being able to move freely from place to place; to be secure against violent assault, including sexual assault and domestic violence; having opportunities for sexual satisfaction and for choice in matters of reproduction.

4. Senses, Imagination, and Thought. Being able to use the senses, to imagine, think, and reason - and to do these things in a "truly human" way, a way informed and cultivated by an adequate education, including, but by no means limited to, literacy and basic mathematical and scientific training. Being able to use imagination and thought in connection with experiencing and producing works and events of one's own choice, religious, literary, musical, and so forth. Being able to use one's mind in ways protected by guarantees of freedom of expression with respect to both political and artistic speech, and freedom of religious exercise. Being able to have pleasurable experiences and to avoid non-beneficial pain.

5. Emotions. Being able to have attachments to things and people outside ourselves; to love those who love and care for us, to grieve at their absence; in general, to love, to grieve, to experience longing, gratitude, and justified anger. Not having one's emotional development blighted by fear and anxiety. (Supporting this capability means supporting forms of human association that can be shown to be crucial in their development.)

6. Practical Reason. Being able to form a conception of the good and to engage in critical reflection about the planning of one's life. (This entails protection for the liberty of conscience and religious observance.)

7. Affiliation.

a) Being able to live with and toward others, to recognize and show concern for other humans, to engage in various forms of social interaction; to be able to imagine the situation of another. (Protecting this capability means protecting institutions that constitute and nourish such forms of affiliation, and also protecting the freedom of assembly and political speech.)

b) Having the social bases of self-respect and non-humiliation; being able to be treated as a dignified being whose worth is equal to that of others. This entails provisions of non-discrimination on the basis of race, sex, sexual orientation, ethnicity, caste, religion, national origin and species.

8. Other Species. Being able to live with concern for and in relation to animals, plants, and the world of nature.

9. Play. Being able to laugh, to play, to enjoy recreational activities.

10. Control over one's Environment. 
a) Political. Being able to participate effectively in political choices that govern one's life; having the right of political participation, protections of free speech and association.

b) Material. Being able to hold property (both land and movable goods), and having property rights on an equal basis with others; having the right to seek employment on an equal basis with others; having the freedom from unwarranted search and seizure. In work, being able to work as a human, exercising practical reason and entering into meaningful relationships of mutual recognition with other workers.

This list is designed specifically for human beings but most of the items have similar counterparts for many organisms, as explained in Nussbaum (2018). Life, bodily health, bodily integrity, and emotions, are already in the animal list. Senses, imagination and thought is an item that is formulated in a very human-centered way, but could be adapted to other species. Affiliation, relation to other species and nature, and play, are more relevant to socially oriented species and less to others. Practical reason and control over one's environment have something similar for animals, which do some forms of goal-motivated action and planning, and certainly do enjoy control in order to obtain what they prefer. Even political control is part of this in social species with power hierarchies.

The similarity between lists designed for animals and lists designed for human beings is rather promising, and many of these considerations can apply to other nonhuman organisms. But a lot of work remains to be done to build practical methods that build bridges between the measurements of each item for various species. When discussing application of the list to animal issues, Nussbaum $(2006,2018)$ focuses on the usefulness of the list for articulating animal rights and related policies, but does not explore how to compare the levels of achievements of various items of the list across species.

One issue that deserves special exploration here in the context of inter-species comparisons is the inequality in "normal" levels of functionings across species. This issue is relevant to all approaches, including hedonism, but it is convenient to discuss it for objective functionings. Let us take longevity as the lead example here. The animal list does not refer to longevity and focuses on instantaneous conditions of comfort. Nussbaum's list, in contrast, refers to the ability "to live to the end of a human life of normal length" and "not dying prematurely." How do we extend that to other species? As mentioned earlier, dogs live up to 12-17 years whereas humans live up to 80-100 years. In the objective approach, there seem to be only two options in this respect, and none is fully satisfactory.

The first option consists in normalizing longevity to the usual lifespan of the species. For dogs, we would simply substitute the new sentence "to live to the end of a dog life of normal length." A dog who dies at 7 is considered to suffer a loss due to premature death comparable to a human being who dies at 45 . The problem with the normalization is that it fails to recognize relevant inequalities. Some breeds of dogs live longer than others. This seems to be a clear advantage, because even if we have little idea of dog's views on time and longevity, when they appear to have a good life it seems sad when it is shortened and good when it lasts longer. Similarly, if we 
found a cure to dog ageing and could use it to expand the life of dogs to come closer to the lifespan of their human friends, wouldn't that be an improvement for both species, but especially for the dogs? The normalization approach wouldn't recognize an expansion of the normal lifespan of a species as an improvement at all. In fact, the problem is already there for human beings. If we lifted the bounds to our longevity, it would be odd to say that, after normalizing our index of longevity, the situation has not improved for the human species.

The second option consists in refusing to normalize and treat a shorter lifespan of a species as a disadvantage. Insofar as nothing can be done about it, this is not really a problem. We could regret that dogs have shorter lives and pity them for this disadvantage, but since this is hard to change, this has little consequence for practical action. But in fact, something can be done about it, because in the contemplated approach, there are multiple dimensions, and a disadvantage in one dimension can be compensated, to some extent, by an advantage in another approach. But it would seem odd to say that we would like to be especially concerned about the comfort of dogs because of their shorter longevity. Mice, whose lifespan is even shorter, would then deserve an extra concern for their comfort, and so on to some extreme, particularly considering other groups of organisms such as bacteria.

So we have a conundrum. Either we normalize, and inequalities in normal capacities are insufficiently recognized, or we don't, and these inequalities appear excessively important. Vallentyne (2005) has examined this problem in depth, but in the specific context of egalitarianism, i.e., an approach that gives extreme priority to the worse-off. Assuming that mice have a lower well-being than humans, because of the lower level of most of their functionings, Vallentyne articulates an approach that simultaneously considers mice to be equally well-off as humans when their functionings are proportional to the capacities, while allowing that enhancement of their capacities can appear desirable. The main building stone of his approach is an index of "moral standing" of an individual organism that does not depend on its species identity but on its capacities in the course of action that is followed. If a mouse is not enhanced, it has low capacity and therefore low moral standing. If its level of functioning relative to its capacities is then comparable to that of a human being, they are considered equally well-off even if the mouse is actually at a very low level of functioning. If a mouse is enhanced, its moral standing rises accordingly, and its situation will be assessed relative to its new level of capacity. The fact that moral standing moves with the capacity in the current situation makes it possible to give a low level of functioning to the non-enhanced mouse and a higher level to the enhanced mouse, while remaining within the bounds of what is acceptable for egalitarianism.

Vallentyne's solution gives very little value to enhancing per se, actually, since the well-being of an organism is assessed relative to the moving reference of capacities in the contemplated alternative. Enhancement that greatly raises the capacity of an individual but does not proportionally increase its functioning is then considered to have little value. This seems strange. If we could double the lifespan of a dog when he has reached 15 years already, should we judge that this has not produced a valuable outcome if the dog has a fatal accident at 25 , because proportionally to his potential longevity this has reduced his lifespan? Relatedly, since the moral standing of the individual organism depends on the chosen action, one does not wrong 
an individual organism by reducing its capacities, provided that the functionings are not reduced more than proportionally. Consider two mice. They have a different genetic setup and only one is amenable to enhancement. If they end up experiencing the same level of functioning and no enhancement is practiced, can we really say that they have received equal treatment? It seems that the one who could have been enhanced has suffered from a worse treatment.

We propose the following monotonicity principle: An organism who has higher levels both in capacity and in achievement (actual functioning) than another organism is better off. This principle is incompatible with normalizing functionings by the capacity level, independently of whether this capacity level is measured as the one in the course of action that is taken (as in Vallentyne's approach) or as the maximum capacity among those that are achievable across the various courses of action that are feasible. In contrast, it is compatible with an approach that treats both functionings and capacities as contributing positively to well-being.

Of course, the monotonicity principle strongly clashes with what we could call the maximum principle, according to which two individual organisms are equally well-off if their functionings are at the maximum of their capacities. The two principles point in radically different directions about how to assess an ecosystem with multiple species. The monotonicity principle sees tremendous inequalities everywhere and, assuming some degree of inequality aversion, advocates investing in enhancing the capacities of the various organisms. The maximum principle, in contrast, is perfectly happy if all species live at a good level relative to their respective capacities.

The maximum principle may prima facie seem more reasonable and closer to standard approaches to ecosystem analysis, but it is suspect. It condones the capacities that Nature has distributed, and there is little to be said in defense of such deference to Nature, when it becomes possible to alter the capacities of some organisms. The human species has been working hard at enhancing its own capacities by constructing artefacts and exploring the mechanisms of the world, and it would be strange to argue that this does not represent substantial progress, even if one may have doubts about the particular direction taken (e.g., excessive exploitation of natural resources) and the use made of the new capacities. There is a strong tension between seeing the human species as superior in some important respects (primarily cognitive capacities) and seeing inequalities between species as innocuous. Except, of course, if one is happy with the domination of the human species over the others. But from a species-neutral perspective, it is hard to value certain objective performances (in capacities and functionings alike) and not see tremendous inequalities in the natural world.

Another argument against the maximum principle is that, in the species-neutral context, it should also be applied among human beings. Are we willing to say that individuals with disabilities are as well-off as others provided they have reached their capacities? The fact that their capacities can be altered by transforming their environment or their own characteristics and that hard investments are made to that effect shows that the maximum principle is completely rejected among human beings. If it is rejected among human beings, then non-anthropocentrism requires rejecting it also across the species boundaries. 
A third argument against the maximum principle can be found in science fiction. Imagine that a more advanced species landed on Earth, peacefully settled and lived a sort of life that would make us tremendously jealous but would be completely beyond our own capacities. Wouldn't it be strange if they said that everything is fine because we humans, just like them, are enjoying the best of our capacities? Suppose they could do some research toward enhancing us and would consider this to be of little value because we are at the maximum of our current capacities. Wouldn't we strongly object and argue that we suffer from the huge inequalities between us and them? As a matter of fact, the huge inequalities in the world already produce a similar gap between those whose conditions from the womb on are the most propitious and those who are repeatedly stressed with various forms of aggression and whose potential is blighted right from the beginning. These inequalities are obviously unjust.

One could venture a defense of the maximum principle by referring to the deaf community, which is adamant against the view that being deaf is a disadvantage in itself. What the deaf community is actually showing to the rest of the world is that many structures in place (voice and sound communications and signals in public places and transportation, norms for work meetings, cultural memes associating deafness and dumbness) are designed ignoring them and could be easily adjusted. But the most interesting aspect of this example is that the deaf community claims to benefit from special functionings that others do not have access to, such as a special and valuable culture. The claim is definitely not that deafness warrants redefining flourishing in a more modest way, through a suitable renormalization, for the deaf people.

All of these arguments suggest that while anthropocentrism is expelled officially from the analysis, it is always lurking and trying to come back in different garbs. The maximum principle may represent such a disguised way of justifying the prerogatives of the human species. Rejecting the maximum principle and accepting the monotonicity principle, however, does not raise the threat, examined by Vallentyne (2005), that we should devote all our resources to the disadvantaged species such as the mice, or if we were to consider a more extreme case, the bacteria. Vallentyne was examining how to apply a strong version of egalitarianism across species, but with a less extreme version, one can avoid the threatening conclusion about resource reallocation by noting that actually our ability to alter the capacities of species is now very limited, and that the gains in well-being that we are able to provide to individual members of "low-level" species are minuscule. So, in a moderate version of egalitarianism or prioritarianism, we should indeed pay attention to the interests of all species and give special priority to the most disadvantaged, but since we cannot in most cases alter the fundamental characteristics of the most disadvantaged species that make them disadvantaged (e.g., bacteria easily perish under changing environmental conditions), this does not require starving our own species for the sake of the others.

So far, we have mostly been dealing with the selection, measurement and scaling of dimensions of well-being. But once the lists are established, the question of weighting comes back in full force. A good example of the problems it generates comes from the social items. Some species are very social and do have important 
determinants of well-being in their social interactions, or even in interaction with other species (e.g., pets and domesticated animals interacting with human beings or with other domesticated species). But other species (e.g., bobcats) live mostly solitary lives and it would be questionable to declare them worse off for that reason. Therefore, such species would need to put a lower weight on the social items in the list. How can one proceed in this respect? One suggestion is to rely on evolutionary considerations and examine how fitness and species development depend on various combinations of the items. Concretely, one could regress a measure of evolutionary fitness on the various items, over a data set spanning multiple combinations of life conditions, and take the coefficients of the regression as reflecting the relative importance of the items for that species. But this approach makes evolutionary fitness the ultimate measure and this is debatable. There is no reason why fitness and well-being should necessarily go together. Natural selection might favor some traits that are good for reproduction but not particularly good for individual wellbeing. A variant of this proposal would look at where the co-evolution of species has been going, and take this state as the yardstick by which the situation of particular individuals should be gauged. But there is no reason to assume that co-evolution is optimal for all species, since it may actually produce a situation in which some are oppressed by others, or exploited in a questionable way. And defining the target state does not provide a method for weighting the various dimensions, and it seems that such a weighting system is necessary for the assessment of the situation of individuals who fall short of the optimal situation in some dimensions more than others, in all sorts of combinations.

We are therefore back into the same type of conundrum as at the end of the previous section. The various items in the objective list cannot be weighted without some idea of an external measure of well-being that provides a sense of the relative importance of the items. But the aim of the list was precisely to build such a measure, and if such a measure was already available we might not need the list at all, except, perhaps, for policy purposes that require knowing the determinants of well-being for adjusting interventions.

\section{Preference based}

In standard welfare analysis, preference-based approaches involve relying on individual ordinal preferences (i.e., how individuals rank possible lives) in order to build indices of well-being through some indexation method. In Adler and Fleurbaey (2016), two such approaches are highlighted, which measure degrees of preference satisfaction in a different way. However, both rely on the same general idea of equivalence. Here is how the equivalence principle works. Define a subset of reference situations that can easily be ranked by some simple dominance principle, i.e., in that subset, it is obvious and not controversial at all how to rank situations. Then, evaluate any individual situation by the position of the reference situation that is judged as good by the individual as that individual's current situation. Concretely, if one individual's situation is equivalent (according to that individual) to the reference situation $\mathrm{S}^{*}$, while another individual's situation is equivalent to the reference situation 
$\mathrm{S}^{* *}$, then who is better off is decided simply by comparing $\mathrm{S}^{*}$ to $\mathrm{S}^{* *}$. Examples are provided below.

The motivation underlying this principle is that, once one is confident about how to rank the reference situations across individuals with all possible preferences, then out of respect for their preferences, their situations outside the reference set must be assessed by how the individuals themselves compare their own situations to the reference situations.

In one prominent application of this principle, the non-market dimensions of quality of life are given a reference value and preferences are used to carry people into a hypothetical situation in which they enjoy the reference values for the nonmarket aspects, together with a level of "equivalent income" that is computed so as to make this hypothetical situation look as good, in their eyes, as their current situation. For instance, someone with mediocre health and an income of $\$ 70,000$ per year might equally like good health with an income of $\$ 60,000$, and therefore the latter income level is treated as a measure of their well-being. This adjustment of income for quality of life aspects is rather natural, though the choice of reference values may be contentious, and is consequential for the measurement.

In another application of the equivalence principle, individuals are carried into a hypothetical situation in which they face a lottery between a very bad situation and a very good situation, and the probability of obtaining the better situation is adjusted so that they consider their current situation equivalent to facing such a lottery. The probability of the better situation is then used as a measure of their well-being. This method has been used commonly in the measurement of health (in the so-called "QALY" approach), but can be used more broadly for all aspects of life combined. Again, the choice of the benchmark situations is delicate and consequential for the measurement. This particular method relies on people's risk attitudes, and the more risk averse individuals will typically require a higher probability, which puts them at a higher level of the measure. There are variants of the approach that make the more risk-averse individuals appear less well-off than the others, though.

These two particular applications of the general equivalence principle, as detailed in Adler and Fleurbaey (2016), cannot be applied directly to non-human organisms. Animals do not have income levels that can be adjusted in hypothetical situations, and they cannot offer their views about facing risk about extreme situations which may be far from their current situations. Is the general equivalence principle impossible overall, because it relies on individual preferences? Many people unfamiliar with ethology share the anthropocentric prejudice that other organisms do not really have preferences like human beings. But there is a well-established field of research that studies the elicitation of animal preferences. "Research on animals' preferences is commonly used as a tool in the study of animal welfare. Fundamental to this research is the assumption that animals make choices that are in their own best interests, and that allowing animals to live as they prefer will ensure a high level of animal welfare" (Appleby et al., 2018, K8541-8543). This last sentence echoes the reasons, in strikingly similar terms, why (human) individual preferences are so central in standard welfare analysis performed in economics. Animal preference studies even examine if non-human animals prefer to have control or to obtain what they desire (answer: it depends, 
sows and hens prefer to make their own nests but gerbils are not averse to prepared holes), estimate the elasticity of demand for certain products to the price (in terms of effort) that must be paid to get them, and also study the aversion to risk and uncertainty (which depends on personality traits). In most respects, nonhuman animals behave very much like humans, with quite rational patterns overall (their preferences are transitive), although their capacities for planning appear sometimes much more limited than in humans.

We believe that the equivalence principle may offer a way to solve the weighting problem of the objective list approach. Moreover, it may also offer a way to assuage the worry that inequalities are inflated by a measurement that does not normalize the levels of functionings by the corresponding capacities of the different species.

Here is a proposal for an application of the equivalence principle across species. Define a list of all the functionings over which any species may have preferences. If some functionings are beyond the capacity of a species, or are irrelevant to it for some reason, then simply consider that members of this species are indifferent about this dimension. This is perhaps questionable. For instance, humans are unable to fly with their own body but they are certainly not indifferent to flying, and they have been devising artefacts enabling them to fly. So a lack of natural capacity need not mean a lack of preferences or a complete indifference. But it may be reasonable to assume that the application of this approach would be done for large-category functionings encompassing multiple specific things. For instance, mobility may be more relevant than the exact means of transportation that are used. In that case, most species have some level of functioning and some preferences with respect to mobility.

Define a path of reference situations in the space of functionings, and for that purpose, take a path that follows, as closely as possible, the scatterplot of typical members of the different species, carving a middle way among the whole scatterplot. The reason why taking a middle way is important is the following. One species may be more able to excel in one functioning $\mathrm{F}$, and is likely to have a greater preference for it. If the reference path has a mix of functionings that associates its level of functioning $\mathrm{F}$ with higher levels for other functionings, the fact that this species likes this functioning more will attenuate the relative loss it suffers in the other functionings. This is because, given its preferences, the situation on the path that it considers as good in its current situation will include a lot of functioning $\mathrm{F}$ and therefore good levels for the other functionings as well. Therefore, different species that specialize in different types of functionings will appear rather well off in their disparate niches even if their level of functioning is low in some dimensions. For instance, a relatively a-social species may care little about social integration, and then the conspicuous loneliness of its members will not appear as a serious disadvantage.

If a particular path that is not in the middle was adopted (e.g., one that followed the mix of functionings for human beings), then the other species would appear excessively well-off if they do not care much about particular functionings which humans prefer (e.g., thought). The equivalence principle has the property that outliers (those whose actual situation is far from the path) tend to be considered well-off if their situation fits their preferences and they do not care for the dimensions in which their functionings are low. Taking a path that follows one species will tend to show this species as relatively disadvantaged. Taking a 


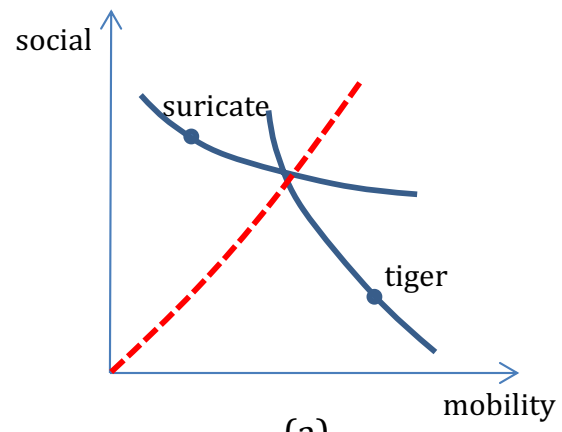

(a)

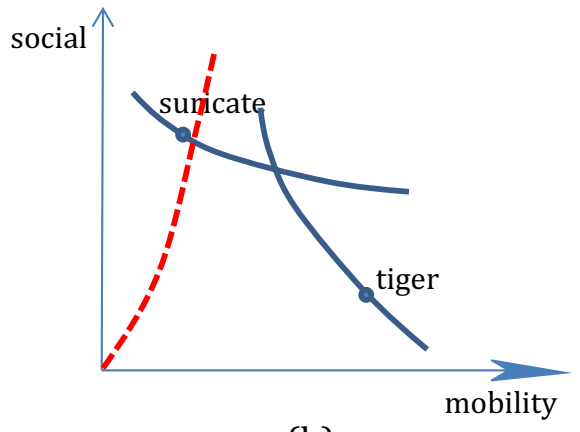

(b)

Fig. 1 Locating the reference path for the equivalence principle

middle path puts all the species on an equal footing in terms of taking account of their preferences in comparing them to all the other species.

We can illustrate this reasoning graphically. Consider two functionings, e.g., social bonding and mobility, and consider two species that are unequally specialized in them, e.g., suricates for social bonding and tigers for mobility. Suricates may care more about being able to exercise their social bonding abilities, while the tigers may care a lot about mobility (though this may be instrumental to their survival, but for the sake of simplicity let us accept this assumption).

On panel (a), a middle path makes the two species appear equally well-off, each of them exhibiting a greater preference for their side of the space, i.e., for the functioning they are good at. In contrast, on panel (b), a path that is closer to the suricates' situation will make the tigers appear artificially better off (Fig. 1).

The idea of relying on preferences may be harder to extend to species which are more passive (like plants) and for which avoidance and seeking behavior may not be easily observed. But relying on what seems beneficial to the typical member of the species for the expression of its potential may still provide a good guide for species-tailored weighting systems.

Relying on specific weights across the various dimensions of functionings is a way to reduce the worries about an excessive measurement of inequalities due to specialization when a normalization by capacities is not adopted. This may seem dubious because the fact that one species is very good in one dimension (e.g., social bonding) makes it appear well-off, and even better-off after taking account of its preference for this dimension. But the correlation between preferences and capacities is good for all species, and plays a role that is similar to, but not as extreme as, normalization by capacities. If every species is an outlier with respect to some dimension in which it excels and which it enjoys particularly, then that is a reason to consider it relatively well-off in comparison with other species. Human beings are good at thinking and not great at many other physical feats, but that is fine because they care a lot about their mental life. Dogs are excellent at smelling, and visibly seem to enjoy sniffing around, so this is good for them in 
the equivalence approach. An application of the approach that takes broad-category functionings may miss some of these specialization effects, though.

The equivalence approach would provide an interesting solution to the problem of heterogeneous needs if it were possible for individual members of a species to imagine what life would be like if they had the needs of another species. But that seems farfetched. A better solution probably consists in selecting functionings that are on the output side rather than the input side. For instance, one should take the nutritional state of the organism as the relevant functioning for food rather than the calorie intake. The functionings listed in the previous section appear to follow this output strategy and this seems the most promising way to deal with this issue. In conclusion to this section, we believe that specific weights are a promising direction of research, and for many species the notion of preferences appears to provide a valuable guide for this. A purely objective approach that would seek to apply the same weights to the dimensions of life across all species would appear too insensitive to what makes every species able to enjoy life in its own way. In particular, if one goes back to the objective lists that have been proposed for animals, such as the Five Freedoms, this approach seems particularly attractive to fill in the blanks in the elusive notion of "expressing normal behavior."

The equivalence approach may perhaps provide an alternative way of measuring "welfare potential" for the Budolfson and Spears (2020) approach. Instead of relying on a proxy like the number of neurons, one can directly measure well-being on the reference path, taking the ideal situation of an organism in a particular species, both in terms of achieved functionings and preferences about this functioning mix, and consider this as the best level an organism of this species is generally able to reach. Then most organisms would fall below this level and it would be easy to measure their well-being in terms of the decomposition.

\section{Achieved level $=$ potentia $1 \times$ percentage of achievement.}

Taking stock, in light of this section, we would like to propose a third principle, the preference principle, according to which if an organism has a relative specialization in a functioning, its well-being depends positively on how much it cares about this functioning. This principle appears quite plausible, and, in the context of the equivalence approach, it requires locating the reference path in the middle of the scatterplot of species, as we have argued. It makes all species look good thanks to their respective specializations and preferences.

The monotonicity principle, which has been proposed as more attractive than the maximum principle, and inspires the method followed in this section by not normalizing functionings, is actually not fully satisfied by the equivalence approach. Indeed, two organisms at the same levels of functionings can be deemed unequally well-off if their different preferences project their current common situation to a different situation on the reference path. By extension, an organism who is less successful in all functionings than another can be deemed better off if, according to its preferences, its mix of functionings is great and is projected on a high point on the reference path. The monotonicity principle is satisfied, nevertheless, for organisms close to the reference path as well as for organisms with similar preferences. As 
Fleurbaey and Blanchet (2013) argue, the monotonicity principle ignores one aspect of well-being which is absent from the list of functionings, namely, the fit between preferences and the composition of functionings. Being more successful in all functionings may not mean much if organisms are not happy about this particular mix. Therefore, in the end we find it reasonable, when taking account of preferences, to accept violations of the monotonicity principle when this is justified by differences in preferences.

While we have focused in this section on a version of the equivalence approach that relies on a single path in the functioning space, it is of course possible to test what happens with different possible paths. It is also possible to combine several paths in a single measure, e.g., by computing well-being as the average score for several measures based on different paths. Such average measures may have interesting properties, especially because they are even more sensitive to individual preferences (because different paths cross an indifference curve at different points, the averaging approach registers more features of the shape of indifference curves).

It should be acknowledged, before we close this section, that preferences may not always be a good guide to well-being. Behavioral studies of human decision have shown that human preferences are often inconsistent and violate basic canons of rationality (Shafir, 2016). The same issue is bound to be raised for other species, and in particular, problems with overspecialization and addiction have been observed in animals. Therefore some work needs to be done to sort out the "respectable" preferences from the problematic ones. In the case of human decision, there are explorations along these lines (e.g., one can correct for myopia over long-term decisions), although this very much remains preliminary. Similar efforts would need to be done for other species.

\section{Functionings across species}

In this section we examine how certain functionings can be compared across species, through two examples. The first one is health and the second one is habitat. As suggested before, we assume that if an organism has a relative specialization in a functioning, its well-being depends positively on how much it cares about this functioning.

In Sect. 1, we discussed considerations of interactions associated with the collective contributing to a "healthful" state, where an unimpacted "stable" ecosystem might generally be considered to experience greater well-being than an unstable system, although the experience of each individual could vary vastly to either extreme in the stable or unstable system. We aspire to achieve "health" in many aspects of our human existence, not just physically but also, e.g., in our relationships, habits, communities, and work-life balance. As previously discussed, "ecosystem health" is variously defined according to goods and services provided to humans (with effective metrics for measurement and management yet undetermined and under heavy debate), as well as according to similarity with historical, less-impacted conditions (Palmer \& Febria, 2012), the latter indicating human impacts to ecosystems constitute a deviation from health. 
The health of an individual inhabiting any such ecosystem might be considered a crucial contribution to well-being but such consideration does not eliminate the need to design some measure of comparable health functionings between species. The World Health Organization (1948) defines health as “ ... a state of complete physical, mental and social well-being and not merely the absence of disease or infirmity." This definition, of course, risks blurring the distinction between health as a particular set of functionings and well-being as a comprehensive measure, as understood in this paper. But some gauge of physical well-being likely constitutes the most easily achievable measure. However, obvious measures with known similarity across species are often the most extreme and indicate a deviation from well-being usually far beyond the possibility for corrective action, such as injury, illness, or death. Ideally, deviation from "health" or "well-being" would be detected much earlier.

We might consider looking to the field of ecotoxicology for comparative quality-of-life benchmarks that could be adapted for consideration of health in different species. This might be appropriate because the negative effects of contaminants are evaluated relative to important processes or qualities: stress, growth, development, reproduction, physiology, immunology, and behavior. These qualities or processes in a variety of organisms meant to represent a variety of taxa important in a variety of important ecological systems have therefore been characterized according to baselines (e.g., an optimal lifespan or activity level) and impacted (e.g., a relative change in lifespan or activity level) conditions. In ecotoxicology, such deviations from baseline are used to predict and detect problems associated with contaminant exposure that might require attention, where we hope to maintain ecological systems in a state of optimal functioning, devoid of significant impacts from contaminants. "Baseline" constitutes an unimpacted or "healthy" condition. We have already discussed problems with some of these, e.g., lifespan, reproduction, and physiology.

"Normal" behavior is generally considered healthy, and indeed, deviations from normal behavior can have important repercussions, e.g., when certain factors alter an individual's environmental or social interactions in ways that might make it more vulnerable to predation, illness, or the elements. And because behavior is a representation of the set of circumstances to which an organism is exposed, it might truly reflect a combination of conditions underlying physical, mental, and social wellbeing, that in principle must align to some extent for a particular behavior to occur. Therefore, deviation from some normal behavior can be considered a deviation from health or wellbeing, and we might use this as a comparable measure of functionings if we can characterize "normal behavior" in each species.

The sensitivity of such a comparison, because, e.g., preference or tolerance can vary within a species, might necessitate determining what range within a particular type of behavior includes all normal behaviors; and a deviation by any particular individual from its normal behavior might still fall within the overall range of normal behaviors for that species and therefore go undetected. However, it might be acceptable to reference a range of normal behaviors and accept that preferences of some hopefully small number of individuals will not be detected when a change from a more preferred activity to a less preferred activity falls within that range of normal behaviors that characterizes the entire species, or population. To increase sensitivity, such ranges could be determined for subsets of species, e.g., a particular 
population inhabiting a particular habitat (akin to the aggregation within each population of a species described in Sect. 1), and not across all individuals of a species in all ranges.

Broom (1991) explains that subjective experiences alone should not define welfare and some indicators that he describes, e.g., body damage, disease, immunosuppression, adrenal activity, and behavioral anomalies, can be measured using biomarkers of stress (or ill health). Additionally, negative mental and social experiences can also be indicated via biomarkers of stress. A measure of stress, anxiety has been compared time and again in humans and non-human animals for the purpose of understanding if pharmaceutical drugs can help humans, i.e., mechanisms underlying responses in non-human animal models are extrapolated to human subjects (e.g., Groenink et al., 2015; Holsboer \& Ströhle, 2005; Martin, 1998; Schmidt \& Muller, 2006; Treit, 1985), but non-target anxiety-related behavior has also been documented in fish exposed to environmentally relevant concentrations of antidepressants intended for humans (Martin, 2019). Application of these studies, usually of rodents, might be used for consideration of ecosystem well-being, e.g., instead, outcomes to non-human test-subjects can be considered relative to their own health and well-being. At a glance, such comparisons seem to be met with the same concerns discussed about, e.g., use of hormone concentrations, and other physiologic measures to compare functionings, in Sect. 3. However, biomarkers of stress elicited before a behavioral or other phenological change becomes apparent can increase the sensitivity and possibly the comparability of equivalent measures of functionings when species-specific reactions downstream to similar molecular effects that biomarkers exploit otherwise diverge and thus cloud interpretation. Additionally, such earlier indications of deviation from health and well-being can to an even greater extent preclude harm if used as a benchmark for corrective action. Therefore, cellular and molecular mechanisms underlying stress, e.g., detected via glucocorticoids (Cockrem, 2013; Lane, 2006) or fatty acid composition (Filimonova et al., 2016), might be used to detect deviations from physical, mental, and social well-being. Increasingly less invasive methods and advances aiding understanding of withingroup variation, e.g., in glucocorticoid secretion (Cockrem, 2013; Lane, 2006), might provide promise for comparing such functionings between species and therefore constitute a possible means to compare health and well-being between species.

Consider habitat quality as another example, which is at least as challenging as health because the concrete forms of habitat vary considerably across species. As a consequence, what can be measured and compared across species is not directly the physical quality of habitat, but the adequation of habitat with the individual organism's preferences. Environmental manipulation constituting the alteration of an organism's surroundings or relocation to an alternate setting might influence wellbeing and therefore provide essential evidence to gauge habitat quality. Although, obviously, some species will have more or less direct control over their surroundings than others, preferences elicitation might indicate not just what an organism likes but also whether an organism or a species cares more about it, and therefore how important habitat might be to well-being..

Preference tests of habitat complexity indicated eastern box turtles preferred an enriched environment with cypress mulch substrate, shredded paper, and a box 
for hiding over only a flat newspaper substrate (Case et al., 2005). Zebrafish and checker barbs preferred a structured over a simple compartment, and the latter used particular areas of the structured compartment more (Kistler et al., 2011). Nile tilapia preferred a gravel enriched environment but after one day showed no preference between a non-enriched environment or one with gravel or a shelter (Delicio et al., 2006). Rats preferred the most complex environment of four offered (Denny, 1975) as well as familiar stimuli when in an unfamiliar environment, and novel stimuli when in a familiar environment (Sheldon, 1969).

Particulars of habitats can be further distilled, e.g., rainbow trout preferred temperatures around 18C (Myrick et al., 2004) and their color preferences differed according to temperature, subsequently influencing growth and later color preferences (Luchiari \& Pirhonen, 2008). Zebrafish preferred a dark over a light environment (Serra, 1999), and personalities in zebrafish (Rey et al., 2015) and Nile tilapia (Cerqueira et al., 2016) influenced temperature preference, proactive fish for higher and reactive fish for lower temperatures. Sows preferred warmer floors during the three days after the onset of farrowing (Phillips et al., 2000), and weanling pigs preferred fresh air over ammoniated air (Smith et al., 1996). Animals clearly show preferences for their surroundings, and even have personalities, but again anthropocentrism is integral when we select tested preferences (and we risk confounding preferences with familiarity) (Fraser \& Matthews, 1997) and therefore such an approach in this context also needs work, e.g., Matthiopoulos (2003) discusses important spatial considerations of habitat use in reference to preference and Maia and Volpato (2016) propose a weighted history-based method to detect the strength of preferences.

These methods and observations do not appear yet to provide a direct way of comparing the importance of habitat quality across different species, but a similar approach as for health might be conceived. Insofar as certain markers of normal behavior, health or stress can be associated with various habitats, one could establish a ranking of habitats and relate various levels within such a ranking for different species.

Varying reproductive strategies and life history characteristics also challenge such a preference-based approach. For instance, individual members of species characterized as K-selected might alter their surroundings more by actively changing particular elements or by moving to new surroundings, whereas r-selected species tend to blanket the landscape with many progeny where subsequently a few that hit the right spot are able to survive and persist, a very different strategy. If we focus on the things that most studies consider, i.e., preference reflected by a choice of surroundings made by the individual, then we might bias consideration of well-being toward $\mathrm{K}$-selected species. One might argue that the apparent need to sense and react to one's surroundings in the case of K-selected species makes them more cognizant and thus more able to experience perception associated with well-being. That said, r-selected species don't distribute their progeny completely randomly, e.g., a female mosquito exercises preference when she lays her eggs and that influences subsequent progeny (options of the current generation influence the future generation).

To sum up, these examples suggest that comparing functionings that are complex and involve some degree of subjectivity, like health and habitat, is possible 
by relying on physiological and behavioral markers. Proof of the concept will only come, admittedly, when studies experiment with methods that truly focus on comparable characteristics.

\section{Conclusion}

We started this paper with the question whether the concepts of social welfare analysis need a complete overhaul, or can be extended easily. Arguably, neither is the case. Easy extension is not what we anticipated, and certainly was not around the corner, but a complete overhaul does not seem necessary either. Among the various approaches examined here, perhaps the objective-list and the preferencebased approaches are the most promising because they are the most flexible. They indeed do not presuppose a focus on very partial functionings, such as control over resources or energy, or mental states, all aspects which are at least partly relevant for some species but do not have a clear universal scope.

Inter-species comparisons of well-being are, therefore, not of a different nature than intra-species comparisons. In both cases one must accommodate differences across individual organisms in terms of needs, abilities, personalities and preferences. But the much greater variability of these characteristics, across species, is certainly quite challenging. We have argued against the maximum principle, which is excessively accepting of inequalities in capacities, and argued instead in favor of two core ethical principles: the monotonicity principle, which recognizes certain differences as true inequalities, and the preference principle, which supplements and tempers the monotonicity principle by granting an advantage to specialization.

With two examples (health and habitat) we have sought to pave the way for interspecies comparisons in specific functioning domains. Interestingly, they both suggest that relying on "normal" or "preferred" states as the benchmark against which deviations can be assessed is the most promising approach, which implies two things: first, some subjectivity and reference to preferences is unavoidable even to measure particular functionings, before one thinks of aggregating over domains to obtain a comprehensive measure of well-being; second, since normal behavior is associated with a general state of well-being, it is actually hard to pin down very specific functionings in a way that is both comparable across species and not directly indicative of a broader set of functionings. One can measure the speed of mobility of a particular individual organism in a purely objective and narrowly defined way, but one cannot assess its health state or the quality of its habitat without having an idea of how well-off, broadly speaking, this individual is.

We believe this first step toward a cross-specific theory of well-being validates the project to develop an approach that is both fully species-neutral and statusquo-independent. The latter is satisfied at least in the sense that the presence of a species in a particular place would not give it priority over other species. But in practice, the stability of ecosystems and the "normality" that guides assessment of well-being for health, habitat and presumably many other functionings makes it hard to avoid any dependence to some type of status quo. When baseline conditions evolve, due to environmental circumstances (e.g., climate change) or human 
intervention (such as habitat destruction or domestication), one has to consider if we adapt the rods by which well-being is estimated, and this may reveal a weakness in the approach suggested in our examples. For instance, platypuses may have lost a good part of their health and well-being due to the reduction in their numbers and, thus, their inability to live in large groups as they did before, but it is now impossible to assess how this change in their "normal" life really affects them, because of the lack of observations of the previous normal state. But our proposed methodology reflects proven practice in biology which can serve as a useful guide for the development of applied studies of well-being.

We have left important issues aside, as announced in the beginning. In particular, we have focused on individual well-being and inter-individual comparisons and have not addressed issues about collective aggregation, such as population ethics or the added value, above and beyond the collection of individual well-being levels, of collective structure and purpose. But the approaches to well-being examined here are amenable at least to take account of the effects on the individual organism of social interactions, within and between species. And aggregation by the usual "social welfare function" tools can readily incorporate the value of distributional characteristics of the situation of the population. What is still missing is a methodology to assess the separate value of truly collective achievements, that would be similar to the methodology that assesses the value of individual achievements.

To conclude, we hope this work will encourage the development of a research field at the intersection of biology, economics, and philosophy, which will articulate adequate concepts and design practical methods to assess and compare the well-being of different organisms, including human beings among them, in a unified framework. The separation of animal welfare studies and social (i.e., human) welfare analysis in academia is a form of intellectual Apartheid that cannot stand the test of ethics. Moreover, this separation is arguably counterproductive. Most theories of human welfare focus on people who have standard abilities and an extended access to the market, and are ill-suited for those who do not enjoy such conditions. More inclusive theories are needed.

This direction of research can contribute to transforming environmental economics and agricultural economics, where policy analysis remains largely anthropocentric. Pollution and climate change do not merely raise an intergenerational challenge for human beings. The interest in how the future is discounted in environmental economics should be supplemented with an equally intense interest in how other species are counted. And just as the balance sheet of plantations should have accounted for the conditions endured by slaves, farming and various land uses should be analyzed including the impact on domesticated animals and wildlife. In recent work, Espinosa and Treich (2021), with a model expanding the model proposed by Blackorby and Donaldson (1992) for laboratory animals, show that depending on whether farm animals' lives are worth living, a greater weight on animal well-being in social welfare analysis may lead to recommending a decrease or an increase in the quantity of animals raised and eaten. As they argue, "animal welfare will probably be a major topic in the twenty-first century." (p. 540). 
Acknowledgements We thank the editor and three referees for excellent guidance in the revision of the paper, and participants at the Duke workshop on animal welfare, as well as Richard Bradley, Mark Budolfson, Paula Casal, Sara Constantino, Yann Kervinio, Nicolas Treich for helpful comments. Christy Leppanen was supported by the Nancy Gore Hunger Professorship in Environmental Studies at the University of Tennessee. This work was assisted through participation in the DySoC/NIMBioS Investigative Workshop: Extending the Theory of Sustainability, December 5-7, 2018, at the National Institute for Mathematical and Biological Synthesis, supported by the National Science Foundation through NSF Award \#DBI-1300426, with additional support from The University of Tennessee, Knoxville.

Funding This work was assisted through participation in the DySoC/NIMBioS Investigative Workshop: Extending the Theory of Sustainability, December 5-7, 2018, at the National Institute for Mathematical and Biological Synthesis, supported by the National Science Foundation through NSF Award \#DBI1300426, with additional support from The University of Tennessee, Knoxville.

\section{Declarations}

Although the author is an FDA/CTP employee, this work was not done as part her official duties. This publication reflects the views of the author and should not be construed to reflect the FDA/CTP's views or policies.

Conflict of interest The authors have no conflicts of interest regarding the contents of this paper.

Open Access This article is licensed under a Creative Commons Attribution 4.0 International License, which permits use, sharing, adaptation, distribution and reproduction in any medium or format, as long as you give appropriate credit to the original author(s) and the source, provide a link to the Creative Commons licence, and indicate if changes were made. The images or other third party material in this article are included in the article's Creative Commons licence, unless indicated otherwise in a credit line to the material. If material is not included in the article's Creative Commons licence and your intended use is not permitted by statutory regulation or exceeds the permitted use, you will need to obtain permission directly from the copyright holder. To view a copy of this licence, visit http://creativecommons.org/licen ses/by/4.0/.

\section{References}

Adler, M. D. (2013). Well-being and fair distribution. Oxford University Press.

Adler, M. D. (2019). Measuring social welfare. Oxford University Press.

Adler, M. D., \& Fleurbaey, M. (Eds.). (2016). Oxford handbook of well-being and public policy. Oxford University Press.

Appleby, M. C., Olsson, I. A. S., \& Galindo, F. (2018). Animal welfare (3rd ed.). CABI.

Arrhenius, G. (forthcoming). Population ethics. Oxford University Press.

Asaba, A., Okabe, S., Nagasawa, M., Kato, M., Koshida, N., Osakada, T., Mogi, K., \& Kikusi, T. (2014). Developmental social environment imprints female preference for male song in mice. PLoS ONE, 9(2), e87186. https://doi.org/10.1371/journal.pone.0087186

Baluska, F., \& Mancuso, S. (2009). Plant neurobiology: From sensory biology, via plant communication, to social plant behavior. Cognitive Processing, 10, S3-S7.

Benevenuto, R. F., Hegland, S. J., Topper, J. P., Rydgren, K., Moe, S. R., Rodriguez-Saona, C., \& Seldal, T. (2018). Multiannual effects of induced plant defenses: Are defended plants good or bad neighbors? Ecology and Evolution, 8, 8940-8950.

Bentham, J. (1789). An introduction to the principles of morals and legislation. Clarendon Press.

Berridge, K. C. (2003). Comparing the emotional brains of humans and other animals. In R. J. Davidson, K. R. Scherer, \& H. H. Goldsmith (Eds.), Series in affective science. Handbook of affective sciences. Oxford University Press.

Blackorby, C. B., \& Donaldson, D. (1992). Pigs and guinea pigs: A note on the ethics of animal exploitation. Economic Journal, 102, 1345-1369. 
Broom, D. M. (1991). Animal welfare: concepts in measurement. Journal of Animal Science, 69, 4167-4175.

Broussear, D. J., \& Baglivo, J. A. (2005). Laboratory investigations of food selection by the Asian shore crab, Hemigrapsus sanguineus: algal versus animal preference. Journal of Crustacean Biology, 25, 130-134.

Budolfson, M., \& Spears, D. (2020). "Public policy, consequentialism, the environment, and non-human animals. In D. W. Portmore (Ed.), The Oxford Handbook of Consequentialism.Oxford University Press.

Bunford, N., Andics, A., Kis, A., Miklósi, A., \& Gácsi, M. (2017). Canis familiaris as a model for noninvasive comparative neuroscience. Trends in Neurosciences, 40, 438-452.

Case, B. C., Lewbart, G. A., \& Doerr, P. D. (2005). The physiological and behavioural impacts of and preference for an enriched environment in the eastern box turtle (Terrapene carolina carolina). Applied Animal Behavior Science, 92, 353-365.

Cerqueira, M., Rey, S., Silva, T., Featherstone, Z., Crumlish, M., \& MacKenzie, S. (2016). Thermal preference predicts animal personality in Nile tilapia Oreochromis niloticus. Journal of Animal Ecology, 85, 1389-1400.

Clarke, E. (2011). Plant individuality and multilevel selection theory. In B. Calcott \& K. Sterelny (Eds.), The major transitions revisited.MIT Press.

Cockrem, J. F. (2013). Individual variation in glucocorticoid stress responses in animals. General and Comparative Endocrinology, 181, 45-58.

Delicio, H. C., Barreto, R. E., Normandes, E. B., Luchiari, A. C., \& Marcondes, A. L. (2006). A place preference test in the fish Nile tilapia. Journal of Experimental Animal Science, 43, 141-148.

Denny, M. S. (1975). The rat's long-term preference for complexity in its environment. Animal Learning \& Behavior, 3, 245-249.

Donaldson, S., \& Kymlicka, W. (2011). Zoopolis. Oxford University Press.

Driscoll, D. A., \& Watson, M. J. (2019). Science denialism and compassionate conservation: response to Wallach et al. 2018. Conservation Biology, 33, 777-780.

Eichner, T., \& Pethig, R. (2006). Efficient nonanthropocentric nature protection. Social Choice and Welfare, $26,47-74$.

Espinosa, R., \& Treich, N. (2021). Animal welfare: antispeciesism, veganism and a 'life worth living.' Social Choice and Welfare, 56, 531-548.

FAWC (Farm Animal Welfare Council). (1979). Farm Animal Welfare Council Press Statement. 5 December, Surrey, UK (cited in Appleby et al. 2018).

Filimonova, V., Gonçalves, F., Marques, J. C., De Troch, M., \& Gonçalves, A. M. M. (2016). Fatty acid profiling as bioindicator of chemical stress in marine organisms: A review. Ecological Indicators, 67, 657-672.

Fleurbaey, M., \& Blanchet, D. (2013). Beyond GDP. Oxford University Press.

Fleurbaey, M., \& Hammond, P. (2004). Interpersonally comparable utility. In S. Barbera, P. Hammond, \& C. Seidl (Eds.), Handbook of utility theory. (Vol. 2)Kluwer.

Fraser, D., \& Matthews, L. R. (1997). Preference and motivation testing. In M. C. Appleby \& B. O. Hughes (Eds.), Animal welfare.CAB International.

Gil, M. A., Baskett, M. L., \& Schrieber, S. J. (2019). Social information drives ecological outcomes among competing species. Ecology, 100, e02835. https://doi.org/10.1002/ecy.2835

Groenink, L., Verdouw, P. M., Bakker, B., \& Wever, K. E. (2015). Pharmacological and methodological aspects of the separation-induced vocalization test in guinea pig pups; a systematic review and meta-analysis. European Journal of Pharmacology, 753, 191-208.

Gruber, T., \& Grandjean, D. (2017). A comparative neurological approach to emotional expressions in primate vocalizations. Neuroscience and Biobehavioral Reviews, 73, 182-190.

Healy, H. F. (1964). Palatability of herbage and animal preference. Rangeland Ecology \& Management, $17,76-82$.

Heil, M., \& Karban, R. (2009). Explaining evolution of plant communication by airborne signals. Trends in Ecology and Evolution, 25, 137-144.

Holsboer, F., \& Ströhle, A. (2005). Anxiety and anxiolytic drugs. Springer.

Horowitz, A., Franks, B., \& Sebo, J. (2018). Fill-in-the-blank-emotion in dogs? Evidence from brain imaging, commentary on Cook et al. on dog jealousy. Animal Sentience, 2018, 149.

Howe, N. R., \& Sheikh, Y. M. (1975). Anthopleurine: A sea anemone alarm pheromone. Science, 189, $386-388$. 
Johansson-Stenman, O. (2018). Animal welfare and social decisions: Is it time to take Bentham seriously? Ecological Economics, 145, 90-103.

Kahneman, D. (1999). Objective happiness. In D. Kahneman, E. Diener, \& N. Schwarz (Eds.), Wellbeing. The foundations of hedonic psychology. Russell Sage Foundation.

Kistler, C., Hegglin, D., Würbel, H., \& König, B. (2011). Preference for structured environment in zebrafish (Danio rerio) and checker barbs (Puntius oligolepis). Applied Animal Behaviour Science, $135,318-327$.

Lampert, W., Rothhaupt, K. O., \& von Elert, E. (1994). Chemical induction of colony formation in a green alga (Scenedesmus acutus) by grazers (Daphnia). Limnology and Oceanography, 39, $1543-1550$

Lane, J. (2006). Can non-invasive glucocorticoid measures be used as reliable indicators of stress in animals? Animal Welfare, 15, 331-342.

Lang, P. J., \& Davis, M. (2006). Emotion, motivation, and the brain: Reflex foundations in animal and human research. Progress in Brain Research, 156, 3-29.

List, C. (2003). Are interpersonal comparisons of utility indeterminate? Erkenntnis, 58, 229-260.

Luchiari, A. C., \& Pirhonen, J. (2008). Effects of ambient colour on colour preference and growth of juvenile rainbow trout Oncorhynchus mykiss (Walbaum). Journal of Fish Biology, 72, 1504-1514.

Maes, J., Teller, A., Erhard, M., Murphy, P., Paracchini, M. L., et al. (2014). Mapping and assessment of ecosystems and their services. Indicators for Ecosystem Assessments under Action 5 of the EU Biodiversity Strategy to 2020. 2nd Report. European Union, Brussels.

Maia, C. M., \& Volpato, G. L. (2016). A history-based method to estimate animal preference. Scientific Reports, 6, 28328. https://doi.org/10.1038/srep28328

Marder, M. (2013). Plant intelligence and attention. Plant Signaling \& Behavior, 8(5), e23902.

Mariti, C., Carlone, B., Votta, E., Ricci, E., Sighieri, C., \& Gazzano, A. (2017). Intraspecific relationships in adult domestic dogs (Canis familiaris) living in the same household: A comparison of the relationship with the mother and an unrelated older female dog. Applied Animal Behaviour Science, 194, 62-66.

Martin, J. M., Bertram, M. G., Saaristo, M., Fursdon, J. B., Hannington, S. L., Brooks, B. W., Burket, S. R., Mole, R. A., Deal, R. D. S., \& Wong, B. B. M. (2019). Antidepressants in surface waters: Fluoxetine influences mosquitofish anxiety-related behavior at environmentally relevant levels. Environmental Science \& Technology, 53, 6035-6043.

Martin, P. (1998). Animal models sensitive to anti-anxiety agents. Acta Psychiatrica Scandinavica, 98(Suppl. 393), 74-80.

Matthiopoulos, J. (2003). The use of space by animals as a function of accessibility and preference. Ecological Modeling, 159, 239-268.

Mehdiabadi, N. J., \& Schultz, T. R. (2009). Natural history and phylogeny of the fungus-farming ants (Hymenoptera: Formicidae: Myrmicinae: Attini). Myrmecology News, 13, 37-55.

Mench, J. (2019). Advances in agricultural animal welfare: Science and practice. Woodhead Publishing.

Myrick, C. A., Folgner, D. K., \& Cech, J. J., Jr. (2004). An annular chamber for aquatic animal preference studies. Transactions of the American Fisheries Society, 133, 427-433.

Narraway, C., Hunt, J., Wedell, N., \& Hosken, D. J. (2010). Genotype-by-environment interactions for female preference. Journal of Evolutionary Biology, 23, 2550-2557.

Novoplansky, A. (2019). What plant roots know? Seminars in Cell and Developmental Biology, 92, $126-133$.

Nozick, R. (1974). Anarchy, state and utopia. Basic Books.

Nussbaum, M. C. (2006). Frontiers of justice. Harvard University Press.

Nussbaum, M. C. (2018). Working with and for animals: Getting the theoretical framework right. Journal of Human Development and Capabilities, 19, 2-18.

Palmer, M. A., \& Febria, C. M. (2012). The heartbeat of ecosystems. Science, 336, 1393-1394.

Phillips, P. A., Fraser, D., \& Pawluczuk, B. (2000). Floor temperature preference of sows at farrowing. Applied Animal Behaviour Science, 67, 59-65.

Pickett, J. A., Wadhams, L. J., \& Woodcock, C. M. (1992). The chemical ecology of aphids. Annual Reviews of Entomology, 37, 67-90.

Pugh, J. (2016). Driven to extinction? The ethics of eradicating mosquitoes with gene-drive technologies. Journal of Medical Ethics, 42, 578-581.

Rawls, J. (1982). Social unity and primary goods. In A. K. Sen \& B. Williams (Eds.), Utilitarianism and beyond.Paris/Cambridge: Maison des Sciences de 1'Homme/Cambridge University Press. 
Rey, S., Digka, N., \& MacKenzie, S. (2015). Animal personality relates to thermal preference in wildtype zebrafish, Danio rerio. Zebrafish, 12, 243-249.

Robbins, L. (1932). An essay on the nature and significance of economic science. Macmillan.

Robbins, L. (1981). Economics and political economy. American Economic Review, 71(2), 1-10.

Schmidt, M. V., \& Muller, M. B. (2006). Animal models of anxiety. Drug Discovery Today: Disease Models, Nervous System Disorders, 3, 369-374.

Sen, A. K. (1992). Inequality re-examined. Oxford University Press.

Serra, E. L., Medalha, C. C., \& Mattioli, R. (1999). Natural preference of zebrafish (Danio rerio) for a dark environment. Brazilian Journal of Medical and Biological Research, 32, 1551-1553.

Shafir, E. (2016). Inconsistent preferences. In M. Fleurbaey \& M. D. Adler (Eds.), Oxford handbook of well-being and public policy.Oxford: Oxford University Press.

Sheldon, A. B. (1969). Preference for familiar versus novel stimuli as a function of the familiarity of the environment. Journal of Comparative and Physiological Psychology, 67, 516-521.

Singer, P. (1975). Animal Liberation. Avon Books.

Singer, P. (2011). Practical ethics (3rd ed.). Cambridge University Press.

Smith, J. H., Wathes, C. M., \& Baldwin, B. A. (1996). The preference of pigs for fresh air over ammoniated air. Applied Animal Behaviour Science, 49, 417-424.

Spunt, R. P., Ellsworth, E., \& Adolphs, R. (2017). The neural basis of understanding the expression of the emotions in man and animals. Social Cognitive and Affective Neuroscience, 2017, 95-105.

Treit, D. (1985). Animal models for the study of anti-anxiety agents: a review. Neuroscience \& Biobehavioral Reviews, 9, 203-222.

Tschinkel, W. R. (2015). The architecture of subterranean ant nests: beauty and mystery underfoot. Journal of Bioeconomics, 17, 271-291.

Vallentyne, P. (2005). Of mice and men: Equality and animals. Journal of Ethics, 9, 403-433.

Wager, T. D., Barrett, L. F., Bliss-Moreau, E., Lindquist, K. A., Duncan, S., Kober, H., Joseph, J., Davidson, M., \& Mize, J. (2008). The neuroimaging of emotion. In M. Lewis, J. M. Haviland-Jones, \& L. F. Barrett (Eds.), Handbook of emotions (3rd ed.). The Guilford Press.

Wallach, A. D., Bekoff, M., Batavia, C., Nelson, M. P., \& Ramp, D. (2018). Summoning compassion to address the challenges of conservation. Conservation Biology, 32(6), 1255-1265.

World Health Organization (WHO). (1948). Preamble to the Constitution of WHO as adopted by the International Health Conference, New York, 19 June-22 July 1946; signed on 22 July 1946 by the representatives of 61 States (Official Records of WHO, no. 2, p. 100) and entered into force on 7 April 1948. The definition has not been amended since 1948.

Publisher's Note Springer Nature remains neutral with regard to jurisdictional claims in published maps and institutional affiliations. 